\title{
Kalk-alkalen Musalar Graniti'nin Petrografisi, Jeokimyası ve Yukarıgöçek (Bigadiç-Balıkesir) Ametist Oluşumun Kökeni; Kuzeybatı Anadolu (Türkiye)
}

\author{
Petrography, Geochemistry of the Calc-alkaline Musalar Granite and Origin of the \\ Yukarlgöçek (Bigadiç-Balıkesir) Amethyst Formation; Northwest Anatolia (Turkey) \\ Hüseyin ŞAHIN ${ }^{1, a}$, Zafer ASLAN ${ }^{*, 2, b}$ \\ ${ }^{1}$ Balıkesir Üniversitesi, Dursunbey Meslek Yüksek Okulu, El Sanatları Bölümü, Kuyumculuk ve Takı Tasarımı Programı, 10800, \\ Dursunbey/Balıkesir \\ ${ }^{2}$ Balıkesir Üniversitesi, Mühendislik Fakültesi, Jeoloji Mühendisliği Bölümü, 10145, Altıeylül/Balıkesir
}

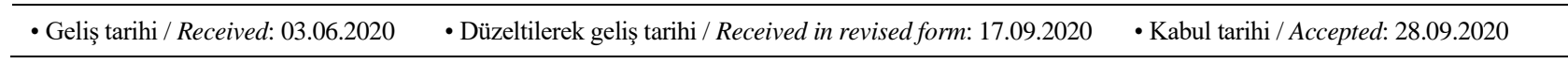

\section{$\ddot{\mathbf{O} z}$}

Bu çalışmada, Yukarıöçek (Bigadiç-Balıkesir) köyündeki ametist oluşumları ve bununla ilişkili Musalar Granitinin jeolojisi ve jeokimyasının incelenmesi amaçlanmıştır. Sakarya zonunda bulunan Biga Yarımadası'da (KB Anadolu) magmatik ve volkanik faaliyetler Oligo-Miyosen döneminde yoğun olarak görülmektedir. Çalışma alanının temelini Paleozoyik yaşlı şistlerden meydana gelen Fazlıkonağı Formasyonu oluşturmaktadır. Birim, Kretase yaşlı ofiyolitik melanj tarafindan tektonik olarak üzerlenmektedir. Tüm bu birimler Oligo-Miyosen yaşlı Musalar Graniti tarafindan kesilmektedir. Petrografik olarak Musalar graniti orta ve iri taneli, yer yer de poikilitik dokuya sahip olup plajiyoklaz, ortoklaz, kuvars, biyotit, amfibol ve opak mineral içermektedir. Jeokimyasal olarak, yüksek potasyumlu ve kalkalkalen karekterli olup I-tipindedir. Büyük iyon yarıçaplı element ve hafif nadir toprak elementlerce zengin olup $(\mathrm{La} / \mathrm{Lu}) \mathrm{N} 13-$ 34 arasında değişmektedir. Tektonik olarak, çarpışma sonrası volkanik yay granitlerinin özelliklerini göstermektedir. Plütonu oluşturan magma ise litosferik manto kökenli olup kıtasal kabuktan etkilenmiştir. Yukarıgöçek köyü civarında bulunan ametistler ofiyolitik kayaçların kırık ve çatlak sistemlerinde $4-5 \mathrm{~cm}$ arasında değişen damarlar şeklinde görülmektedir. Kök ve diş kısımları net olarak görülen ametistlerin rengi genellikle açık mor veya liladır. Ametistler jeokimyasal olarak çok az oranda $\mathrm{FeO}$ ve $\mathrm{MnO}$ içermektedirler. Yapılan sıvı kapanım çalışmalarında homojenleşme sicaklık değerleri $231{ }^{\circ} \mathrm{C}$ ile $278{ }^{\circ} \mathrm{C}$ arasında olup ortalama $255^{\circ} \mathrm{C}$ 'dir. Çalışılan ametist örneklerinin tuzluluk değerleri ile sıvı yoğunluk değerlerinin düşük olduğu ve bunların hidrotermal yol ile oluştukları söylenebilir. Sonuç olarak, Yukarıgöçek köyü ametistleri Musalar granitinin ofiyolitik melanjı kesmesi ve beraberinde getirmiş olduğu silisçe zengin sıvı fazı $255^{\circ} \mathrm{C}$ 'de hidrotermal evrede ofiyolitik melanj içindeki mevcut çatlaklara bırakması ile oluştuğu değerlendirilmektedir.

Anahtar kelimeler: Ametist, Balıkesir, Jeokimya, Musalar Graniti, Sıvı kapanım, Yukarıgöçek

\begin{abstract}
In this study, it is aimed to investigate the amethyst formations in the village of Yukarigöçek (Bigadiç-Balıkesir) and, geology and geochemistry of the associated Musalar Granite. The magmatic and volcanic activities in the Biga Peninsula (NW Anatolia), which are found in the Sakarya zone, are intense the Oligo-Miocene period. The basement rocks of the study area is Paleozoic aged Fazlıkonağı Formation. The units are tectonically overlain by an Cretaceous aged ophiolitic melange. All these units are cut by the Oligo-Miocene age Musalar granite. Petrographically, Musalar granite has medium and coarse grains, occasionally poikilitic texture and contains plagioclase, orthoclase, quartz, biotite, amphibole and opaque minerals. Geochemically, it is high-K, calc-alkaline character and I type granitic rocks. It is rich with large Ion Lithophile Element and light rare earth elements, and the value of $(\mathrm{La} / \mathrm{Lu}) \mathrm{N}$ ranges from 13-34. Tectonically, it shows the characteristics of the after collision volcanic arc granites. The magma of pluton is lithospheric mantle origin and has been affected by the continental crust. The amethysts located in around Yukarlgöçek village have a thickness of 4-5 cm diameter in the ophiolitic rocks and are seen as veins. The color of amethysts, the roots and teeth of which are clearly visible, is usually light purple or lilac. Geochemically amethysts contain very few $\mathrm{FeO}$ and $\mathrm{MnO}$. In the liquid inclusion studies, the homogenization temperature values are between $231{ }^{\circ} \mathrm{C}$ and $278{ }^{\circ} \mathrm{C}$ and the average is $255^{\circ} \mathrm{C}$. It can be said that the salinity and liquid density values of the studied amethyst samples are low and they are formed by hydrothermal way. As a result, the amethysts of Yukarıgöçek village could been formed by the cutting of the ophiolitic melange of Musalar granite and the siliceous rich liquid phase comes in the existing cracks in the ophiolitic melange in the hydrothermal phase at $255^{\circ} \mathrm{C}$.
\end{abstract}

Keywords: Amethyst, Balıkesir, Geochemistry, Musalar Granite, Liquid inclusion, Yukarıgöçek

\footnotetext{
*b Zafer ASLAN; zaslan@balikesir.edu.tr, Tel: (0266) 61214 00, orcid.org/0000-0002-3418-4368

${ }^{\mathrm{b}}$ orcid.org/0000-0002-9997-1012
} 


\section{Giriş}

Türkiye tektonik olarak Torid-Anatolid bloğu, Sakarya zonu, İntra-Pontid sütur zonu ve Zagros sütur zonu olmak üzere dört ana zona ayrılmıştır (Okay ve Tüysüz, 1999) (Şekil 1a). Sakarya zonu, Torid-Anatolid bloğundan İzmir-AnkaraErzincan sutur zonu ile ayrılmıştır (Şengör ve Y1lmaz, 1981; Y1lmaz, 1990). Sakarya Zonu'nda bulunan Batı Anadolu Bölgesi'nde Paleozoyik'den Pliyosen'e kadar değişik yaşlı metamorfik, magmatik, tortul ve piroklastik kayaç çeşitlerinin tümü bulunmaktadır (Şekil 1b). Tetis Okyanus kabuğunun İzmir-Ankara-Erzincan sütür zonu boyunca Sakarya Kitasinın altına dalması ile Üst Kretase'de ofiyolitik kayaçlar (başlangıç yaklaşık 105 my Okay vd., 2006) ve Eosen sonrası da Torid-Anatolid bloğunun Sakarya kıtası ile çarpışmasına bağlı olarak bölgede Tersiyer yaşlı magmatizma etkin olmuştur (Y1lmaz vd., 2001; Okay ve Tüysüz, 1999; Karac1k vd. 2008; Aslan vd. 2017). Orta Eosen'den başlayarak Pliyosen'e kadar devam eden bir volkanizma ile bunlara eşlik eden magmatizma bütün Batı Anadolu'da yüzlekler oluşturur (Şekil 1b). Magmatik kayaçlar tüm birimleri keserek yerleşmiş ve dokanak metamorfik ürünlerini oluşturmuştur. Magmatizma ve volkanizma bölgede çeşitli mineralizasyonların oluşumuna da neden olmuştur (Yiğit, 2009).

Tersiyer magmatizması Batı Anadolu'da doğudan batıya kadar çok geniş alanda yayılım göstermektedir (Ercan vd., 1995; Genç, 1998; Altunkaynak ve Genç, 2008; Okay, 2008). Bu magmatik kayaçlar Eosen, Oligo-Miyosen ve Miyosen olmak üzere üç ana dönemde oluşmuştur. Eosen döneminde magmatik olarak granitik bileşimli plütonik kayaçlar bulunurken, volkanitleri ise andezit ve dasitler oluşturmaktadır. Üst Oligosen-Alt Miyosen yaş aralığında volkanik kayaçlar daha yaygındır ve Biga yarımadasının büyük bir kısmında yüzeyleme vermişlerdir. Andezit, trakiandezit ve bazaltik andezit bileşimli bu kayaçlar çarpışma sonrası volkanizmanın ürünüdürler (Altunkaynak ve Genç, 2008; Prelevic' vd., 2012; Aslan vd., 2017). Bu dönemde volkaniklere eşlik eden plütonik kayaçlar da mevcuttur. Bunlardan biri de çalışmanın konusunu oluşturan Musalar Graniti'dir. Bölgedeki son ürün ise orta-üst Miyosen yaşlı magmatizma olup burada asidik karakterli volkanik kayaçlar daha yaygındır. Kalk-alkalen/alkalen karakterli bu kayaçlar çarpışma sonrası magmatizmanın son ürünleridir.
Dünyada bilinen en önemli ametist oluşumları Uruguay ve Brezilya'da bulunmaktadır. Türkiye'de ise başta Balıkesir olmak üzere Kütahya, Ordu, İstanbul, Çanakkale, Ankara, Afyonkarahisar'da ametist kristali bulunmaktadır (İçözü, 2001). Günümüzde Türkiye'deki en önemli ametist ocağı Güğü Köyü'nde (Dursunbey-Balıkesir) olup özel bir şirket tarafından işletilmektedir. Mor-lila renklerine sahip kuvars grubu minerallerden olan ametist doğal mücevher taşı grubundan olup yarı kıymetli taşlar sınıfında yer almaktadır. Kimyasal formülü $\mathrm{SiO}_{2}$ olan ametistlerde baz1 elementlerin az miktarda bulunuşu renk çeşitliliğini arttırır. Açık leylaktan koyu mora kadar değişen renk çeşitlilikleri vardır. $\mathrm{Fe}^{+2}$ ve $\mathrm{Fe}^{+3}$ elementleri ametis kristalinin mor renkten başlatıp lilaya kadar renklenmesinde etkili olmaktadır (Cohen ve Hassan, 1974; Balitsky vd., 2000). Farklı 1s1larda renk değiştirebilen ametist kristali 1sitıldığında rengi kahverengimsi-sar1 renge dönüşebilmektedir. $400-500^{\circ} \mathrm{C}$ sicaklık aralığında ametist kahvemsi-sarı veya kırmızımsı rengini alırken, $575^{\circ} \mathrm{C}$ üstünde ise rengini kaybederek aytaş1 görünümü almaktadır (Gürbüz, 2007).

Yöredeki magmatizma kalkalkalen özellikte olup genellikle I tipindedir ve volkanik yay granitleri grubunda bulunmaktadırlar. Yitim zonunda oluşan bu kayaçların kökenini üst manto ve kabuk bileşimli hibrit magma oluşturmaktadır (Altunkaynak ve Genç, 2008; Karacık vd., 2008). Çalışmanın konusunu oluşturan ve üst Oligosenalt Miyosen yaşlı Musalar Graniti, İzmir-AnkaraErzincan sütür zonundaki üst Kretase yaşlı ofiyolitik kayaçlarla sokulum yapmıştır (Şekil 1b). Bunun sonucu olarak ofiyolitik kayaçların çatlaklarında mor veya lila renkli ametist kristalleri oluşmuştur. Bugüne kadar granit ve çevre kayacı olan ofiyolitlerden genel jeolojik çalışmalar yapılmış olmasına rağmen jeokimyasal ve petrolojik çalışmalar yapılmamıştır. Ayrıca mevcut ametistlerin özellikleri ve oluşum mekanizması ile ilgili bir çalışmada yoktur. $\mathrm{Bu}$ çalışma ile Musalar granitinin petrografisi, jeokimyası ve petrolojisi tespit edilmiş, ayrıca yan kayaçlarla olan dokanak ilişkileri aydınlatılmıştır. Granit - ofiyolit kayaç dokanaklarında gözlenen ametistlerin sicaklıkları, analizler sonucu tespit edilerek oluşum mekanizması aydınlatılmıştır.

\section{Bölgesel Stratigrafi}

Türkiye, Geç Kretase-Erken Tersiyer'de Gondwana'nın Laurasia ile çarpışması sonucu oluşan Alp orojenik kuşağının bir parçasıdır (Şengör ve Y1lmaz, 1981). Balıkesir şehrinin 81 
km güneydoğusunda yer alan çalışma alanı Biga Yarımadası'nda (KB Türkiye) bulunmaktadır. Biga Yarımadası'ndaki temel kayaçlar Fındıklı, Tozlu, Sarıkız ve Sutüven formasyonlarından oluşan, orta-yüksek metamorfik dereceli Paleozoyik yaşlı Kazdağ Masifi'dir (Dönmez vd., 2005). Kazdağ Masifi, üst Paleozoik yaşlı düşük dereceli metamorfik Kalabak birimi tarafından uyumsuz bir şekilde üstlenilir. Bu birim alttan üste doğru; Orhanlar grovağı, Mehmetalan Formasyonu, Çal Formasyonu, Camialan Kireçtaşı ve Karakaya Formasyonundan oluşan Triyas yaşlı Karakaya Kompleksi tarafindan üzerlenir (Duru vd., 2004; Pehlivan vd., 2007; Akay, 2009). Triyas yaşlı Balya Formasyonu Karakaya Kompleksinin üstüne tektonik olarak gelir. Platform kireçtaşına sahip Geç Jura-Alt Kretase Bilecik Formasyonu tüm birimleri örter (Pehlivan vd., 2007) (Şekil 1b). Üst Kretase'de İzmir-Ankara-Erzincan Sütür Zonu (İAESZ) boyunca ofiyolitik kayaçlar oluşmuştur. Bunlar tektonik dokanaklı olup irili-ufaklı bloklar halinde serpantinleşmiş ultramafit-serpantinit, spilitik bazalt, çamurtaşı, tüf, kiltaşı, rekristalize kireçtaşı, gabro, kumtaşı, aglomera gibi kayaç blokları içermektedir (Duru vd., 2004; Pehlivan vd., 2007). Tersiyer döneminde volkanizma ve magmatizma egemen olup Eosen, Oligosen ve Miyosen dönemlerinde volkanik kayaçlar ve bunlar ile ilişkili plütonik kayaçlar tüm Biga Yarımadası'nda (KB Türkiye) yaygındır (Altunkaynak, 2007). Yöredeki en genç birim Kuvaterner alüvyon.

\section{Materyal ve Yöntem}

Çalışılan alanın ayrıntılı olarak 1/25.000 ölçekli jeoloji haritası hazırlanmıştır. Çalışma alanından 50 adet sistematik örnek alınmıştır. Hazırlanan ince kesitler Balıkesir Üniversitesi Jeoloji Mühendisliği Bölümü Araştırma Laboratuvarındaki Olympos CX31P marka polarizan mikroskopta incelenmiş ve fotoğraflandırılmıştır. Petrografik incelemeler ile seçilen granite ait 7 adet örneğin jeokimyasal (ana, iz ve nadir toprak element) analizleri ACME Analytical Laboratuvarında (Vancouver-Kanada) yaptırılmıştır. Ana ve iz element analizleri Inductively Coupled Plasma (ICP) yöntemiyle, nadir toprak elementleri ise Inductively Coupled Plasma-Mass Spectrometry (ICP-MS) yöntemiyle analiz edilmiştir. Ana ve iz elementleri için 0,2 gr toz örnek $1.5 \mathrm{gr} \mathrm{LiBO} 2$ 'la karıştırılmış ve $\% 5$ HNO3 içinde çözündürülmüştür. Nadir toprak elementler için de 0.25 gr toz örnek dört değişik asitte çözündürülerek analiz edilmiştir. Ana elementler analizinde SO-18/CSC, iz element analizinde SO-18 standartları kullanılmış ve ana elementler $\%$ ağırlık, iz ve nadir toprak elementler ise ppm olarak ölçülmüştür. Arazide çatlak sistemleri dikkate alınarak seçilen beş adet ametist örneğinin sıv1 kapanım analizleri ise İstanbul Teknik Üniversitesi Sivi Kapanım Laboratuarı'nda yapılmıştır. Örneklerden her iki tarafı parlatılmış, 50-100 mikron kalınlığında ince kesitler hazırlanmış ve mikrotermometrik ölçümler Olympos BX51 mikroskoba monte edilmiş Linkam THMSG-600 ve MDSG-600 1sitma ve soğutma sistemlerinde yapılmıştır. Isıtma ve soğutma düzeneği, Leoben Üniversitesi tarafindan hazırlanmış olan sentetik sıvı kapanımı standartları kullanılarak kalibre edilmiştir. Standartlardan yapılan ölçümlerde saf suyun homojenleşme sicaklığ $\left(\mathrm{ThH}_{2} \mathrm{O}\right) \pm 2,0{ }^{\circ} \mathrm{C}$, son buz ergimesi ise $\left(\mathrm{Tm}-\mathrm{H}_{2} \mathrm{O}\right) \pm 0,1{ }^{\circ} \mathrm{C} ; \mathrm{H}_{2} \mathrm{O}-\mathrm{NaCl}$ standardının ötektik sıcaklığı (Te) $\pm 0,2{ }^{\circ} \mathrm{C}$ doğrulukta; $\mathrm{H}_{2} \mathrm{O}-\mathrm{CO}_{2}$ standardının $\mathrm{Te}-\mathrm{CO}_{2}$ değeri $\pm 0,1{ }^{\circ} \mathrm{C}$, Tm-ClTh ise $\pm 0,2{ }^{\circ} \mathrm{C}$ doğrulukta ölçülmüştür. Bir ametist örneğine ait ve iki noktadan yapılan mineral kimyası analizleri ise Minnesota Üniversitesi'nde (ABD) JEOL JXA8900 elektron mikroprobu kullanılarak karbon kaplı cilalı bölümler üzerinde yapılmıştır. Tek tek elemanlar için sayım süresi $20 \mathrm{sn}$ ve numune akımı 20 nA kullanılmıştır.

\section{Bulgular}

\subsection{Litoloji ve Petrografi}

İzmir-Ankara-Erzincan Sütür Zonu'nun hemen güneyindeki bulunan çalışma alanı ve çevresinde metamorfitler, ofiyolitik kayaçlar ve Tersiyer magmatik kayaçları bulunmaktadır (Şekil 2). İnceleme alanında temelini Paleozoyik yaşlı Fazlıkonağı Formasyonu oluşturmaktadır. İnceleme alanında az bir kısımda mostra veren birim, düşük metamorfik dereceli olup serizitşist, kloritşist ve mercekler halinde mermerlerden oluşmaktadır. Şistler genellikle açık kahve yer yer koyu gri, yeşilimsi renk tonlarındadır. Bol foliasyonlu olup, oldukça fazla kırılmaya uğramışlardır. Manganlı tepenin kuzeybatısında gözlenen mercek şeklindeki mermerler ise kirli beyaz ve açık bej renkli olup bol kırık yüzeyleri içermektedir. Birim ofiyolitik melanj ile tektonik dokanakl1 olup dokanak boyunca silisleşmeler egemen olarak gözlenmektedir. Fazlıkonağı Formasyonuna ait lepidogranoblastik doku gösteren şist örneklerinin mineral parajenezi; plajiyoklaz+ klorit+ serizit+ kuvars olarak tespit edilmiştir. Ofiyolitik melanj tabanda serpantinitlerle başlayıp üste doğru radyolarit ve 
çört bloklarına geçmektedir. Birim içerisinde farklı boyutlarda serpantinleşmiş kayaçlar, spilitikmetabazalt, gabro, radyolarit-çamurtaşı, kiltaş1-kumtaşı, kireçtaşı, şist gibi kayaç blokları bulunmaktadır (Yüzer ve Tunay, 2012).

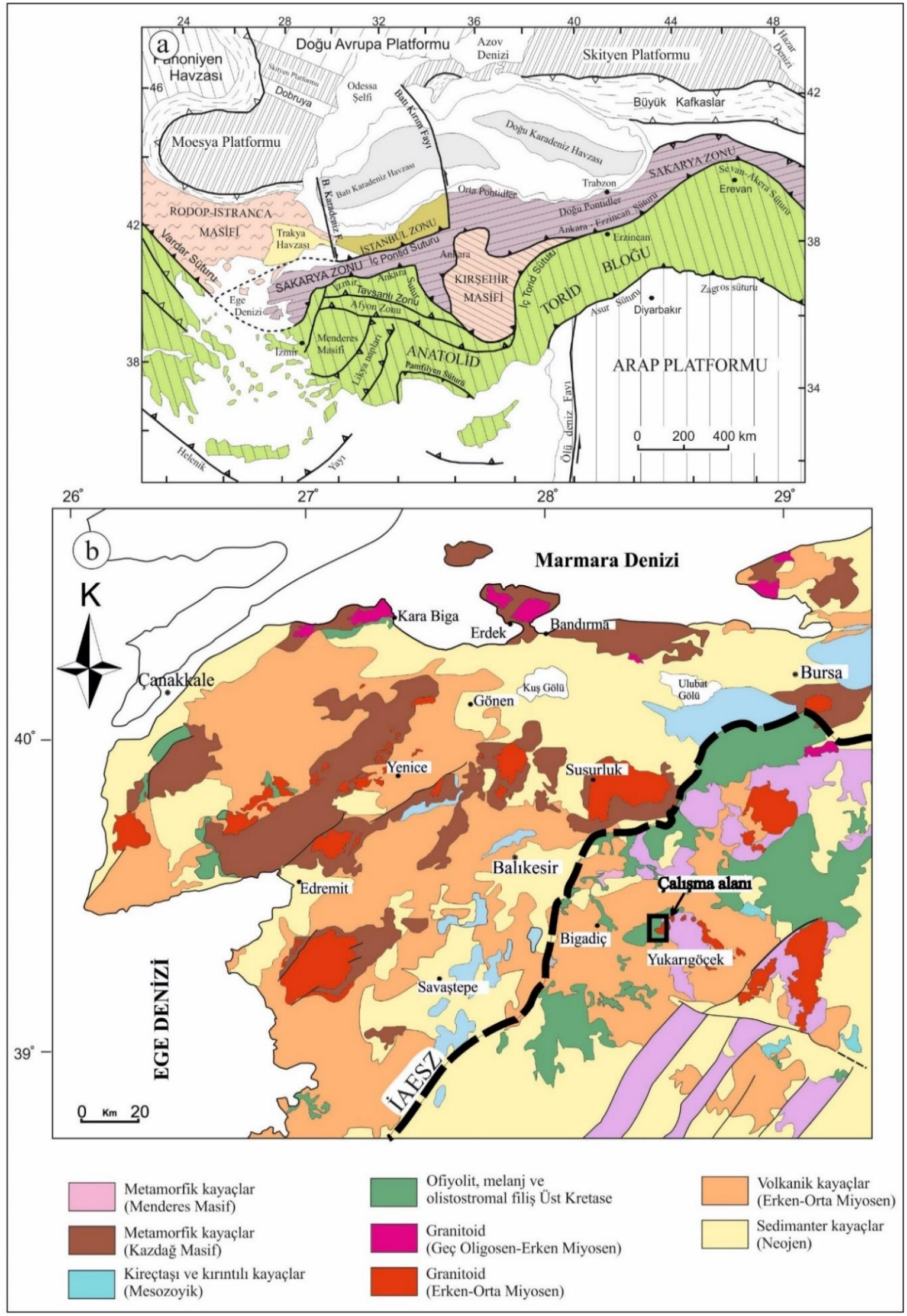

Şekil 1. (a) Türkiye tektonik haritası (Okay ve Tüysüz, 1999), (b) KB Anadolu'nun genel geoloji haritası (Y1lmaz vd., 2000; Okay ve Satır, 2006'dan düzenlenerek). İAESZ; İzmir-Ankara-Erzincan suture zonu 
Çalışma alanında ise bu birimlerden yalnızca serpantinit ve metabaziklere rastlanılmıştır. Yukarıgöçek köyü civarında bulunan yeşil tonlardaki serpantinitler oldukça ayrışmış olup kırıklı bir yapıdır. Metabazik birimler ise çalışma alanının kuzey kesiminde izlenmektedir. Bunlar koyu gri veya siyahımsı gri renklerde olup serpantinitlere göre daha sağlam görünüşlüdür. Musalar Graniti ile olan dokanağı boyunca silisleşmeler yoğun olarak izlenmiştir. Birim içerisinde Yukarı Göçek köyünün hemen kuzeyinde damarlar şeklinde ametist oluşumları gözlenmiştir.

Toplamda $16 \mathrm{~km}^{2}$ ve elipsoidal şekle sahip olan Musalar Granitinin yaklaşık $4 \mathrm{~km}^{2}$ lik alanı çalışma alanında bulunmaktadır. Birim, granit ve granodiyorit karakterli olup KD-GB doğrultuludur ve diğer birimleri keserek yerleşmiştir. Açık gri, gri ve bej renkli Musalar Graniti, oval şekilli ve $1-4 \mathrm{~cm}$ boyutlarında mafik magmatik anklavlar içermektedir (Şekil 3a). Granitik sokulum kayaçı 1-5 $\mathrm{cm}$ boyutlarındaki kuvars damarları ve aplit daykları tarafindan kesilmiştir. Kırıklı ve çatlaklı bir yapıya sahip olan Musalar Graniti'nde arenalaşma (Şekil 3b) ve hidrotermal ayrışma gözlenmektedir. Petrografik incelemede Musalar graniti orta ve iri taneli, yer yer de poikilitik dokuya sahiptir. Petrografik olarak orta ve iri taneli, yer yer de poikilitik dokuya sahiptir. Ana mineral olarak plajiyoklaz, ortoklas, kuvars, biyotit, amfibol ve opak oksit, tali mineral olarak da zirkon, sfen ve apatit içermektedir. Öz ve yarı̈z şekilli plajiyoklazların anortit içeriği \%30-38 arasında olup cinsi andezindir. Albit ikizi yanı sıra büyük bir kısmı halkalı zonlu yapı sunmaktadır (Şekil 3c). Kil ve serizit şeklinde ayrışma gösteren plajiyoklaz mineralleri kırıklı bir yapıya sahip olup kırıklar genellikle uzun eksene dik yöndedir. Öz şekilsiz ve iri kristaller halindeki ortoklazda ayrışma yoğun olup kil şeklindedir. Poikilitik doku (Şekil 3d) gösteren ortoklazlar amfibol, biyotit ve plajiyoklaz inklüzyonları içermektedir. Öz şekilsiz kuvars kristalleri kırıklı bir yapıya sahiptir. Uzun kristaller halindeki biyotit açık kahve-koyu kahve renk pleokroizması göstermektedir. Opak mineral inklüzyonları içeren biyotitler ayrışmadan dolayı kloritleşmiştir. Açık yeşil-yeşil pleokroizma renkleri gösteren amfiboller prizmatik kristaller halinde olup yer yer parçalanmıştır. Amfibol oranı güneyden kuzeye doğru azalmaktadır. Düzensiz geometrik şekiller halinde olan opak mineraller özellikle biyotitlerle beraber bulunmaktadır. Klorit, serizit ve kil ayrışma mineralleri olarak gözlemlenmiştir.

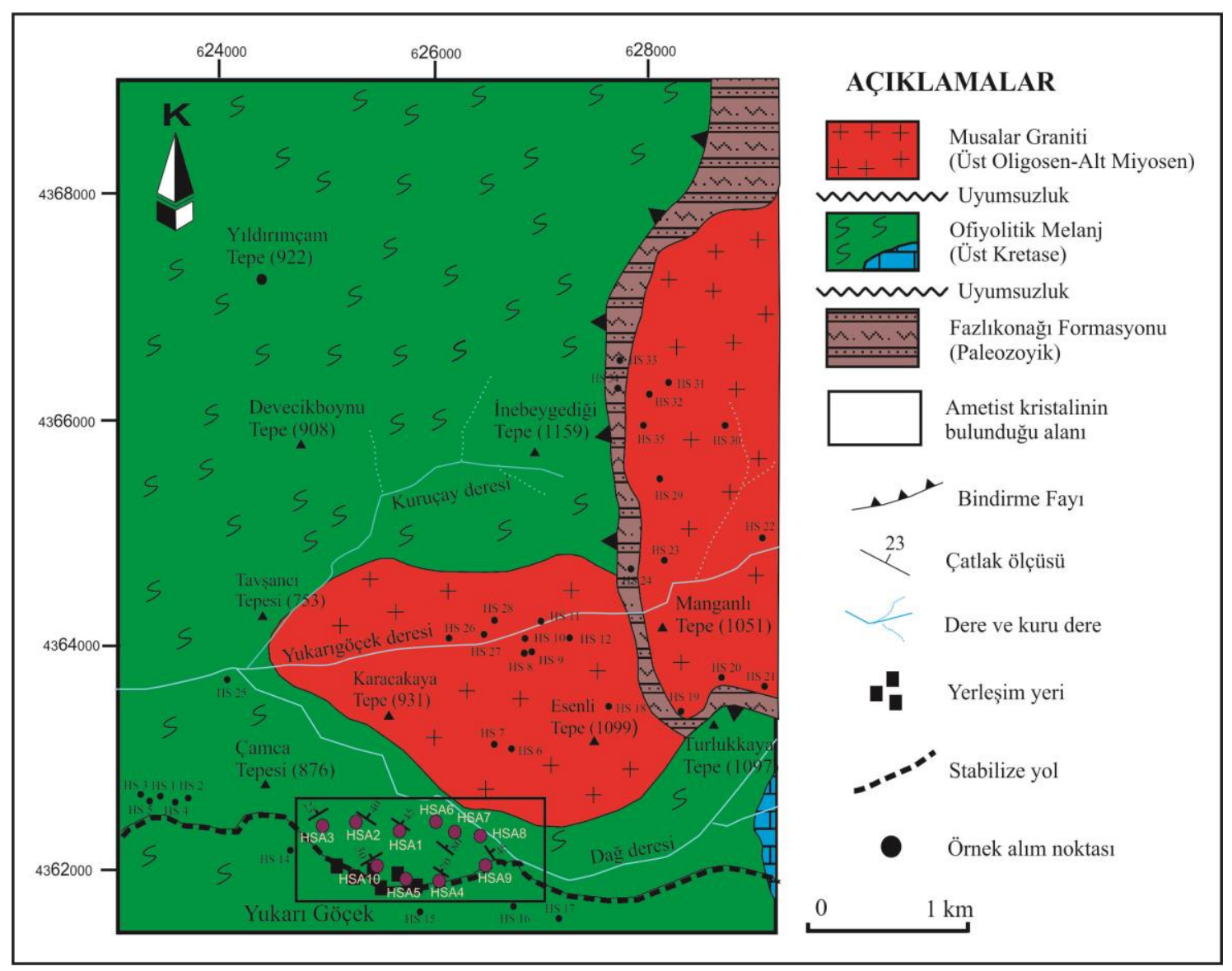

Şekil 2. Çalışma alanının jeolojik haritası 

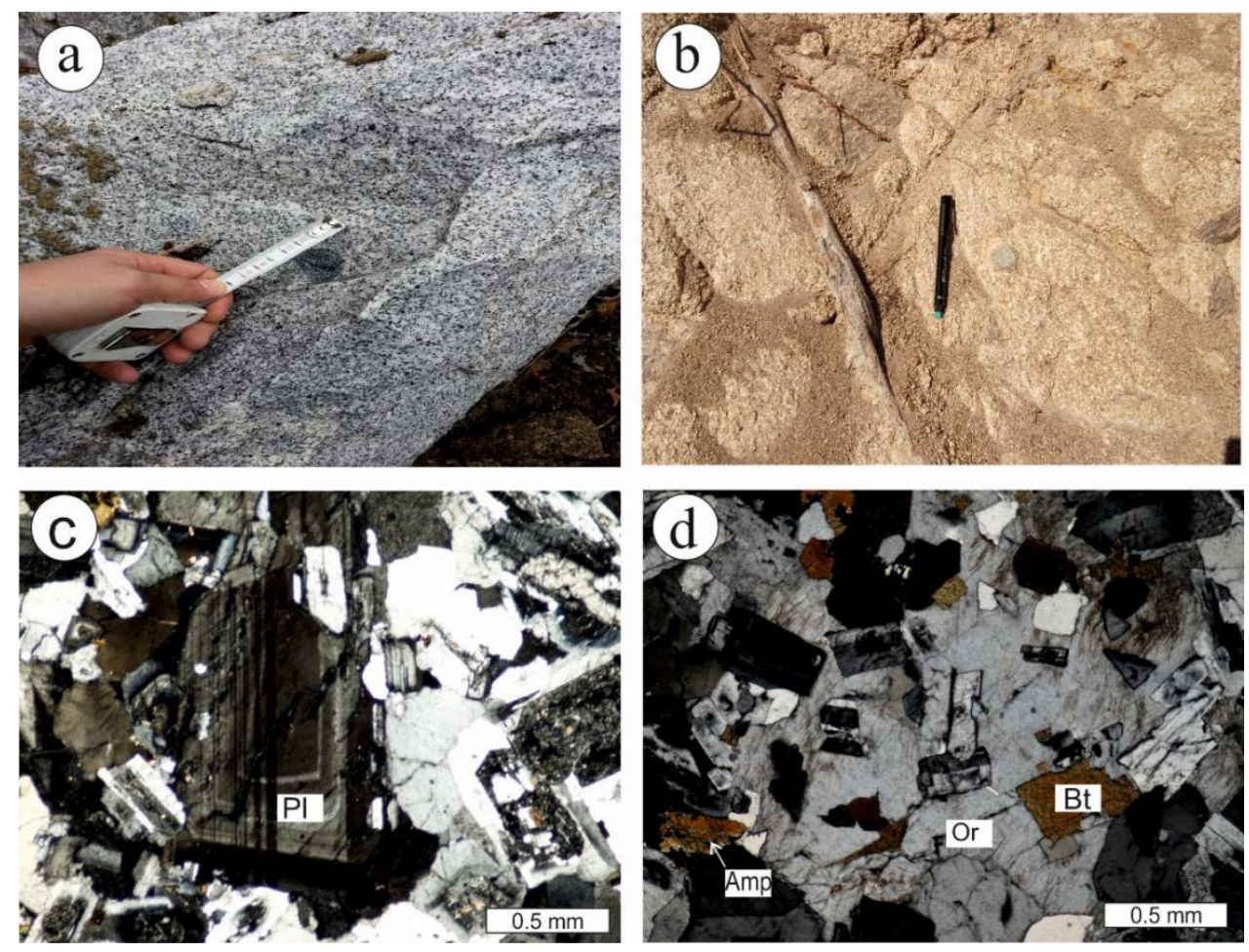

Şekil 3. Musalar Granitine ait. (a) Mafik magmatik anklavlar, (b) Arenalaşma, (c) Halkalı zonlu yapı gösteren plajiyoklaz minerali, (d) Ortoklaz içinde enklüzyon olarak bulunan amfibol, biyotit ve plajiyoklaz minerallerinin oluşturduğu poikilitik doku. Pl: plajiyoklaz, Or: ortoklaz, Bt: biyotit, Amp: amfibol

\section{Tartışma}

\subsection{Musalar Graniti'nin Jeokimyast}

Musalar Granitine ait 7 adet örneğin tüm kayaç ana, iz ve nadir toprak element analizlerinin sonuçları Tablo 1 de verilmiştir. Örneklerde $\mathrm{SiO}_{2}$ $\%$ 66-76, $\mathrm{K}_{2} \mathrm{O} \% 3.0-4.2, \mathrm{Na}_{2} \mathrm{O} \% 3.0-4.3$, $\mathrm{Al}_{2} \mathrm{O}_{3} \%$ 12.6-15.9, $\mathrm{Mg} \# 21-33$ ve $\mathrm{K}_{2} \mathrm{O} / \mathrm{Na}_{2} \mathrm{O}$ oranları $0.76-1.30$ arasında değişmektedir (Tablo 1). TAS sinıflama diyagramına göre Musalar granitine ait örnekler genellikle granodiyorit, bazı örnekler ise granit alanında yer almaktadır (Şekil 4a). Jeokimyasal adlandırma diyagramında elde edilen sonuçlar petrografik verilerle elde edilen sonuçlar ile uyumludur. Alkali-subalkali ayrımı dikkate alındığında ise örneklerin subalkali karaktere sahip olduğu görülmektedir (Şekil 4a). Granitik kayaç örnekleri $\left(\mathrm{Na}_{2} \mathrm{O}+\mathrm{K}_{2} \mathrm{O}\right)-\mathrm{FeO}-\mathrm{MgO}$ üçgen (AFM) diyagramında (Irvine ve Baragar,1971) kalk-alkali alanda bulunmaktadır (Şekil 4b). Sokuluma ait örnekler $\mathrm{SiO}_{2}$ 'ye karşı $\mathrm{K}_{2} \mathrm{O}$ diyagramında genellikle orta-yüksek potasyumlu kalk-alkalen seri alanındadır (Şekil $4 c)$.

Musalar granitine ait örneklerin $\mathrm{A} / \mathrm{CNK}$ değerleri 1-1.1 arasinda olup A/NK $-\mathrm{A} / \mathrm{CNK}$ diyagramlarında (Maniar ve Piccoli, 1989) I-tipi ve peralümin karakterli olduğu görülmektedir (Şekil 4d). Çalışılan granite ait kayaçlarda $\mathrm{SiO}_{2}$ 'ye karşı ana ve iz elementlerdeki değişim diyagramları Şekil 5'de verilmiştir. $\mathrm{SiO}_{2}$ 'ye karşı $\mathrm{MgO}, \mathrm{CaO}, \mathrm{Al}_{2} \mathrm{O}_{3}, \mathrm{Fe}_{2} \mathrm{O}_{3}, \mathrm{TiO}_{2}$ ve $\mathrm{Sr}$ değerlerinde kuvvetli negatif, $\mathrm{P}_{2} \mathrm{O}_{5}, \mathrm{Nb}$ ve $\mathrm{Ba}$ değerlerinde ise hafif negatif ilişki görülürken yalnızca $\mathrm{K}_{2} \mathrm{O}$ değerinde pozitif ilişki görülmektedir (Şekil 5). Gözlenen bu negatif veya pozitif eğilim magmadaki kristal fraksiyonlaşmasına işaret etmektedir. $\mathrm{SiO}_{2}$ 'ye karş1 $\mathrm{Al}_{2} \mathrm{O}_{3}, \quad \mathrm{CaO}$ değerlerindeki değişimler plajiyoklazların, $\mathrm{MgO}$ değerinin azalması amfibolun, $\mathrm{Fe}_{2} \mathrm{O}_{3}$ 'ün değişimi ise amfibol ve $\mathrm{Fe}-\mathrm{Ti}$ oksitlerin kristalleşmesine işaret etmektedir. Böylece sokulumun gelişiminde plajiyoklaz, biyotit ve amfibol ayrımlaşmasının etkili olduğu söylenebilir (Thirlwall vd., 1994). $\mathrm{SiO}_{2}$ 'ye karşı $\mathrm{TiO}_{2}$ ve $\mathrm{P}_{2} \mathrm{O}_{5}$ değerlerinin azalması titanomanyetit ve apatitin kristallenmesi ile ilişkilidir. Musalar granitine ait kayaçların ilksel Manto'ya göre normalize (Sun ve McDonough, 1989) edilmiş element dağılım diyagramında, Büyük İyon Yarıçaplı Elementler (BİYE; K, Sr, $B a$ ve $R b)$, Ce ve Th açısından zenginleşme, bazı Yüksek Çekim Alanlı Element (YÇAE; Y ve Ti), $\mathrm{Ta}$ ve $\mathrm{Nb}$ açısından ise fakirleşme görülmektedir (Şekil 6a). Dağglımda belirgin Nb anomalisi yitim ile ilişkili olup apatit, $\mathrm{Fe}-\mathrm{Ti}$ oksit minerallerin ayrımlaşmasını, Th zenginleşmesi de magmanın 
kabuk etkisini ifade etmektedir. Granitik kayaçların Kondrit'e (Sun ve McDonough, 1989) göre normalleştirilmiş nadir toprak element dağılımlarında, hafif nadir toprak elementlerce zenginleşme, ağır nadir toprak elementlerce daha az zenginleşme gözlenmektedir (Şekil 6b). Musalar granitine ait örneklerde $(\mathrm{La} / \mathrm{Lu})_{\mathrm{N}}$ değerleri 2.74-12.82 arasında değişirken $(\mathrm{La} / \mathrm{Sm})_{\mathrm{N}} \quad 3.11-4.69$ ve $(\mathrm{Gd} / \mathrm{Lu})_{\mathrm{N}} \quad 0.74-1.84$ arasında değişmektedir. Hafif nadir toprak elementlerin ağır nadir toprak elementlere göre daha fazla zenginleşmesi incelenen granitin kalkalkali özellikte olduğunu göstermektedir (Wood ve Joron, 1979; Wilson, 1989). Eu negatif anomali göstermekte olup plajiyoklaz'ın ayrımlaşmasıyla ilişkilidir. Nadir Toprak elementlerinin konkav biçimli dağılımı plajiyoklaz ve hornblend minerallerinin ayrımlaşmasını işaret etmektedir (Thompson vd., 1984; Thirlwall vd., 1994).

Tablo 1. Musalar sokulumuna ait ana oksit (\% ağırlık), iz ve nadir toprak element (ppm) analiz değerleri.

\begin{tabular}{|c|c|c|c|c|c|c|c|}
\hline & HS20 & HS22 & HS23 & HS29 & HS30 & HS31 & HS32 \\
\hline $\mathrm{SiO}_{2}$ & 70.22 & 68.64 & 72.4 & 67.83 & 70.68 & 66.48 & 76.55 \\
\hline $\mathrm{Al}_{2} \mathrm{O}_{3}$ & 14.84 & 15.43 & 14.16 & 15.19 & 14.48 & 15.93 & 12.63 \\
\hline $\mathrm{Fe}_{2} \mathrm{O}_{3}{ }^{*}$ & 2.89 & 3.55 & 2.32 & 3.7 & 2.67 & 3.88 & 1.36 \\
\hline $\mathrm{MgO}$ & 0.87 & 1.07 & 0.7 & 1.38 & 0.94 & 1.41 & 0.71 \\
\hline $\mathrm{CaO}$ & 2.44 & 2.82 & 2.1 & 3.3 & 2.56 & 3.58 & 0.44 \\
\hline $\mathrm{Na}_{2} \mathrm{O}$ & 3.05 & 3.44 & 3.25 & 3.14 & 3.11 & 3.26 & 4.3 \\
\hline $\mathrm{K}_{2} \mathrm{O}$ & 3.98 & 3.33 & 4.26 & 3.31 & 3.65 & 3.05 & 3.27 \\
\hline $\mathrm{TiO}_{2}$ & 0.34 & 0.36 & 0.25 & 0.48 & 0.3 & 0.48 & 0.16 \\
\hline $\mathrm{P}_{2} \mathrm{O}_{5}$ & 0.12 & 0.11 & 0.07 & 0.13 & 0.08 & 0.15 & 0.03 \\
\hline $\mathrm{MnO}$ & 0.05 & 0.04 & 0.05 & 0.07 & 0.06 & 0.09 & 0.02 \\
\hline LOI & 1 & 1 & 0.3 & 1.3 & 1.3 & 1.5 & 0.4 \\
\hline TPLM & 99.80 & 99.79 & 99.86 & 99.83 & 99.83 & 99.81 & 99.87 \\
\hline $\mathrm{Ba}$ & 728 & 934 & 426 & 678 & 633 & 777 & 776 \\
\hline $\mathrm{Co}$ & 3.7 & 5.1 & 3.1 & 5.7 & 3.8 & 5.6 & 0.9 \\
\hline $\mathrm{Cs}$ & 6.6 & 5.4 & 6.8 & 3.1 & 5.2 & 6.6 & 2.7 \\
\hline $\mathrm{Ga}$ & 18.7 & 18.1 & 16 & 17.4 & 15.6 & 17.6 & 12.4 \\
\hline $\mathrm{Hf}$ & 4.4 & 5.5 & 4.7 & 4.3 & 3.3 & 4.3 & 4.6 \\
\hline $\mathrm{Nb}$ & 9.6 & 10.5 & 12.8 & 10.1 & 9.4 & 10.8 & 9.2 \\
\hline $\mathrm{Rb}$ & 150.8 & 124.4 & 180.2 & 117.8 & 134.7 & 114.3 & 80 \\
\hline $\mathrm{Sr}$ & 233 & 291.1 & 177.4 & 279.4 & 222.7 & 344.8 & 42.8 \\
\hline $\mathrm{Ta}$ & 0.8 & 0.9 & 3.5 & 0.7 & 1.6 & 1 & 0.5 \\
\hline Th & 15.6 & 12.3 & 19.6 & 9.1 & 18.4 & 16.4 & 13.5 \\
\hline $\mathrm{U}$ & 3.4 & 3 & 13.5 & 3.3 & 6.3 & 3.5 & 2.8 \\
\hline V & 29 & 43 & 30 & 54 & 30 & 47 & 8 \\
\hline $\mathrm{Zr}$ & 154 & 182.6 & 96.5 & 156.2 & 115.5 & 160.8 & 146.8 \\
\hline $\mathrm{Y}$ & 18 & 20.6 & 42.8 & 19.5 & 24.1 & 23.8 & 31.9 \\
\hline $\mathrm{La}$ & 34.7 & 32 & 22.5 & 23 & 28.7 & 39.9 & 33.3 \\
\hline $\mathrm{Ce}$ & 64.9 & 58.4 & 46.9 & 45.8 & 54.5 & 70.6 & 66.9 \\
\hline $\operatorname{Pr}$ & 7.35 & 6.8 & 5.42 & 5.01 & 5.91 & 7.99 & 7.21 \\
\hline $\mathrm{Nd}$ & 26.5 & 25.8 & 20 & 20.6 & 19.9 & 29.3 & 24.9 \\
\hline $\mathrm{Sm}$ & 5.5 & 4.84 & 4.67 & 3.92 & 4.04 & 5.49 & 5.25 \\
\hline $\mathrm{Eu}$ & 0.73 & 1.13 & 0.52 & 0.94 & 0.76 & 1.06 & 0.67 \\
\hline $\mathrm{Gd}$ & 4.3 & 3.9 & 5.25 & 3.87 & 3.85 & 4.86 & 5.22 \\
\hline $\mathrm{Tb}$ & 0.65 & 0.65 & 0.99 & 0.64 & 0.62 & 0.73 & 0.84 \\
\hline Dy & 3.59 & 3.47 & 6.65 & 4.18 & 3.93 & 4.07 & 5.28 \\
\hline Ho & 0.58 & 0.68 & 1.46 & 0.76 & 0.76 & 0.75 & 1.12 \\
\hline $\mathrm{Er}$ & 1.73 & 2.02 & 4.32 & 1.91 & 2.62 & 2.48 & 3.45 \\
\hline $\mathrm{Tm}$ & 0.27 & 0.31 & 0.8 & 0.33 & 0.39 & 0.37 & 0.49 \\
\hline $\mathrm{Yb}$ & 1.78 & 1.98 & 5.49 & 2.23 & 2.6 & 2.38 & 3.17 \\
\hline $\mathrm{Lu}$ & 0.29 & 0.35 & 0.88 & 0.27 & 0.41 & 0.36 & 0.51 \\
\hline $\mathrm{W}$ & 3.1 & 19 & 0.5 & 0.5 & 1.6 & 1.5 & 1.1 \\
\hline $\mathrm{Be}$ & 6 & 4 & 5 & 4 & 10 & 1 & 1 \\
\hline
\end{tabular}

Toplam demir: $\mathrm{Fe}_{2} \mathrm{O}_{3}(\mathrm{t})$; LOI: Ateşte su kaybı 

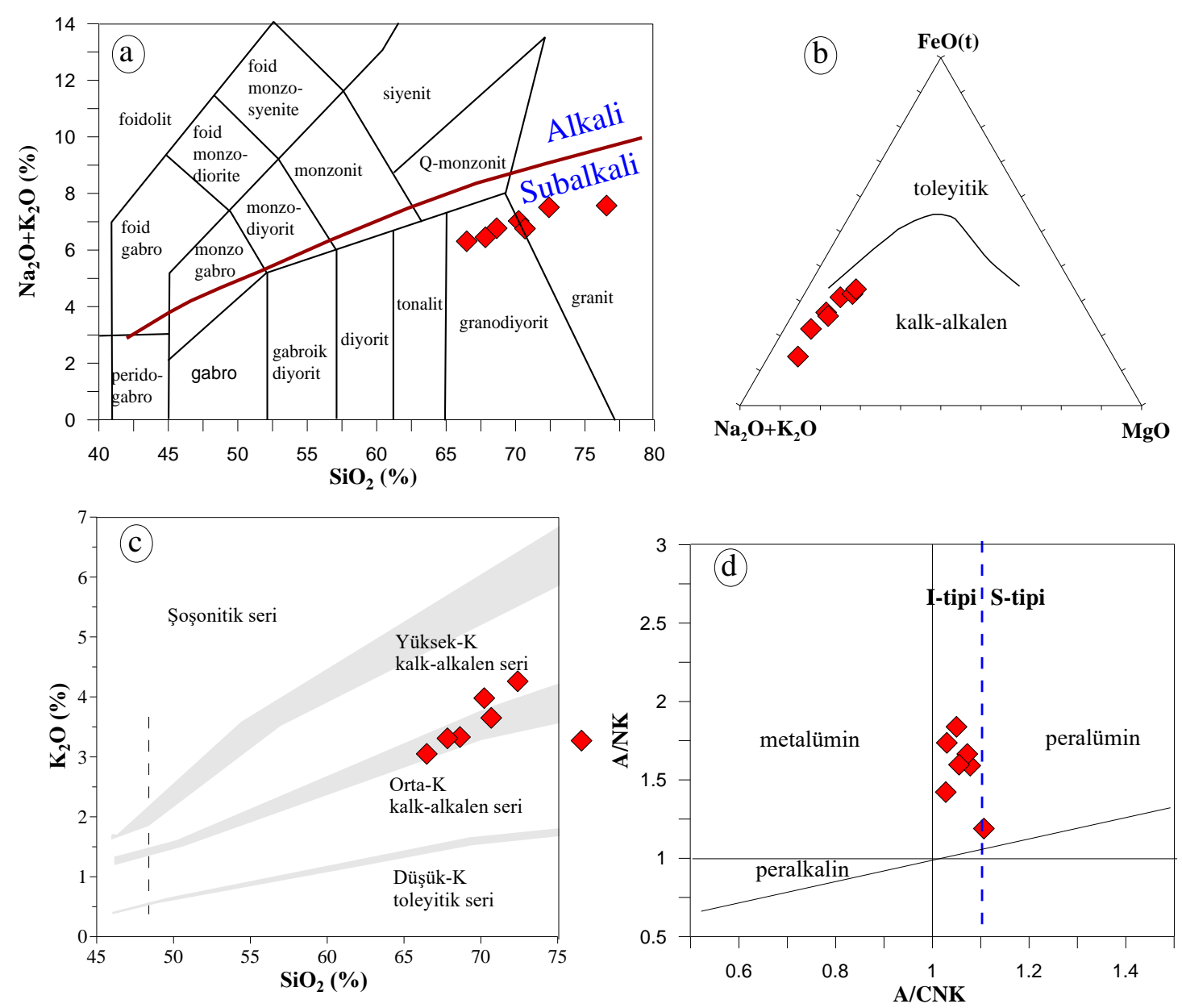

Şekil 4. Musalar Granitine ait; (a) $\mathrm{SiO}_{2}(\%)$ 'ye karş1 $\mathrm{Na}_{2} \mathrm{O}+\mathrm{K}_{2} \mathrm{O}(\%)$ (TAS) diyagramı (Middlemost, 1994) (Alkali-subalkali çizgisi, Miyashiro, 1978'e göredir), (b) AFM diyagramı (kalkalkali-toleyitik çizgisi Irvine ve Baragar, 1971'e göredir), (c) $\mathrm{SiO}_{2}$ (\%)'e karşıllı $\mathrm{K}_{2} \mathrm{O}$ (\%) diyagramı (Le Maitre vd., 2002), (d) $\mathrm{A} / \mathrm{NK}$ karşı (A/CNK) diyagramı (Maniar ve Piccoli, 1989) A/CNK=molar $\mathrm{Al}_{2} \mathrm{O}_{3} /\left(\mathrm{Na}_{2} \mathrm{O}+\mathrm{K}_{2} \mathrm{O}+\mathrm{CaO}\right)$.

Plutonu oluşturan kayaçlar tektonik ortam diyagramlarında değerlendirildiğinde $\mathrm{Rb}-(\mathrm{Y}+\mathrm{Nb})$ diyagramlarında (Pearce vd.,1984) örneklerin çarpışma sonrası volkanik yay granitleri alanına düştüğü görülmektedir (Şekil 7a). Ayrıca, örnekler $\mathrm{Zr}$ (ppm)'ye karş1 $\mathrm{Nb}_{\mathrm{N}} / \mathrm{Zr}_{\mathrm{N}}$ diyagramında (Şekil 7b) yitim ile ilişkili granitoyidler kısmında, R1'e karş1 R2 diyagramında (Şekil 7c) çarpışma sonras1 yükselmeye bağlı alanda ve $\mathrm{Th} / \mathrm{Yb}-\mathrm{La} / \mathrm{Yb}$ diyagramina ise kitasal kenar yayında bulundukları gözlenmektedir (Şekil 7d). Bütün bu veriler 1şığında granitik kayacın tektonik olarak çarpışma sonrası oluştuğunu ve volkanik yay ile ilişkili olduğunu söyleyebiliriz.

Th/U'ya karşı Th ve Th/U'ya karş1 U diyagramlarında (Şekil 8 a, b) Musalar Graniti'ne ait örneklerinin orta-alt kıtasal kabuktan türemiş ergimenin ürünleri olarak tespit edilmiştir. $\mathrm{Nb} /$ La'ya karşı La/Yb diyagramında (Şekil 8c) örneklerin ortalama alt kabuk bileşimine benzer olduğu ve litosferik manto bileşimine karşs1lı geldiği görülmektedir. $\mathrm{Nb} / \mathrm{Th}$ 'a karş1 $\mathrm{Nb}$ diyagramında (Şekil 8d) ise örnekler yay volkanitleri sınırında yer almaktadır. $\mathrm{Bu}$ veriler Musalar granitini oluşturan magmanın orta-alt kıta kabuk etkileşimli oluştuğunu göstermektedir. Batı Anadolu'da oluşan diğer plütonlar incelendiğinde de çarpışma sonrası ve orta kıtasal kabuk etkileşimli oluştukları tespit edilmiştir (Altunkaynak ve Yilmaz 1998; Delaloye ve Bingöl, 2000; Özgenç ve İlbeyli, 2008; Altunkaynak vd., 2012). 

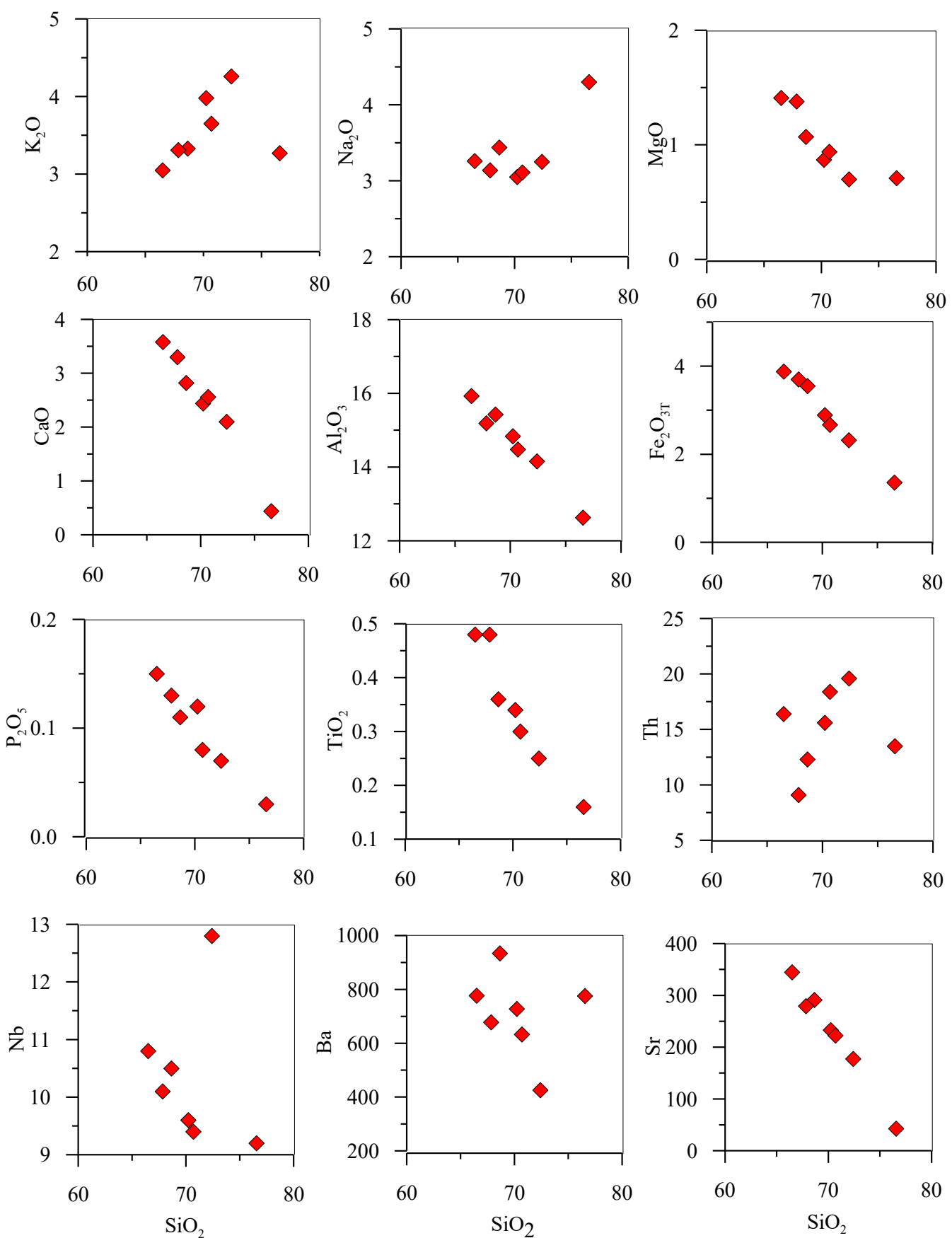

Şekil 5. Musalar graniti ait kayaçların $\mathrm{SiO}_{2}$ (\%)'e karşı ana oksit (\%) ve iz element (ppm) değişim diyagramları
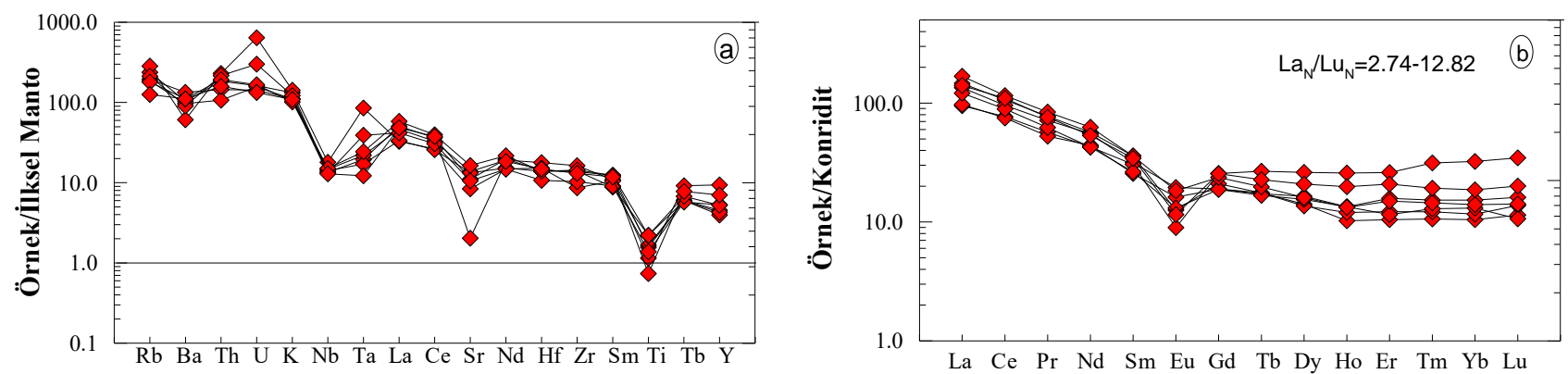

Şekil 6. Musalar Granitine ait; (a) İlksel manto'ya göre normalize edilmiş iz element dağılım diyagramı, (b) kondrite göre normalize edilmiş nadir toprak element dağılım diyagramı (Normalize değerleri, Sun ve McDonough, 1989'dan alınmıştır). 

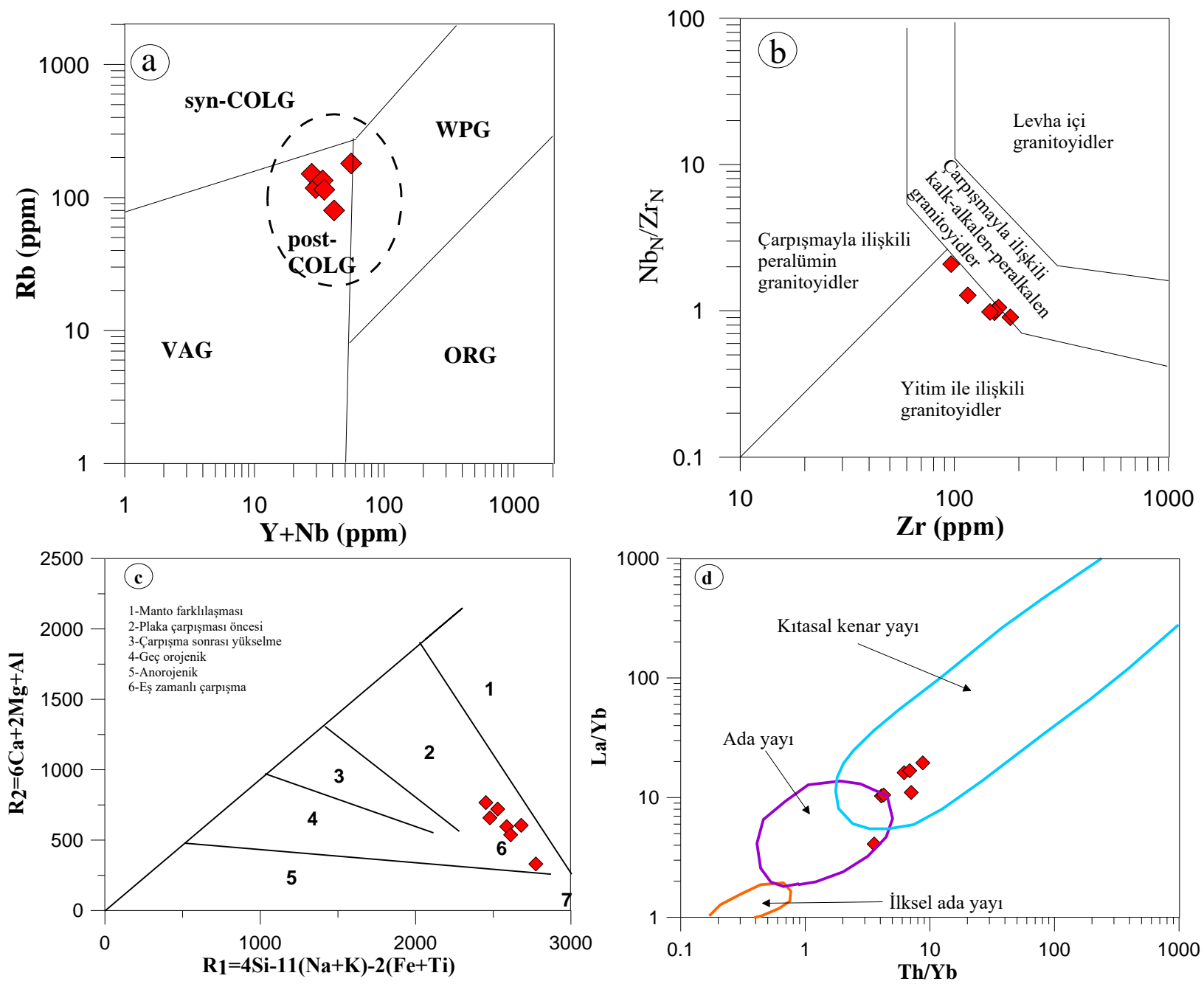

Şekil 7. Musalar granitine ait tektonik diyagramlar; (a) (Y+Nb) (ppm) karş1 Rb (ppm) (Pearce vd., 1984), (b) $\mathrm{Zr}$ (ppm) karş1 NbN/ZrN (Thiéblemont ve Tégyey, 1994), (c) R1-R2, (d) Th/Yb' ye karş1 La/Yb diyagramları (Batchelor ve Bowden, 1985). VAG: Volkanik yay granitleri, syn-COLG: Çarpışma ile eş yaşlı granitler, post-COLG: Çarpışma sonrası granitleri, WPG: Levha-içi granitleri, ORG: Okyanus sırtı granitleri

\subsection{Yukarıöçek Köyü Ametistlerinin Genel Özellikleri}

Türkiye'deki ametist kristalleri pek az araştırmacının çalışma konusu olmuştur (Birsoy, 1983, 1987; İçözü, 2001; Hatipoğlu, 2003; Gürbüz, 2007). Yukarıgöçek köyü ve civarındaki ametistler ofiyolitik kayaçların kırık ve çatlak sistemlerinde 4-5 cm arasındaki kalınlıklarda olup damarlar şeklinde görülmektedir (Şekil 9 a,b,c). Ofiyolitik kayaçlardaki çatlak sistemleri genel olarak K40B 55GB yönündedir. Ametistlerin kök ve diş kısımları net olarak görülmektedir (Şekil 9c). Çatlak aralıklarının küçük olmasından dolayı kristallenme boyutlarıda küçük olarak gelişmiştir.
Kristal rengi genellikle açık mor veya lila (Şekil 9 d, e) şeklinde olup yüzeyde bulunan kristallerin çeşitli fiziki şartların etkisiyle mor renginin kısmen veya tamamen kaybetmiş olma olasılıkları da mevcuttur (Şekil 9 f). Yukarıgöçek köyünde iri ametist kristaller az oranda bulunmakta olup bunlar içerdikleri kapanımlar nedeniyle saydam ve temiz değildir. Balıkesir bölgesindeki ametist kristallerinin mor rengi almasında Fe elementi ile birlikte $\mathrm{Mn}$ ve $\mathrm{Sb}$ elementi de etkili olmuştur (Birsoy, 1987). Ayrıca düşük oranlı radyasyonun da renklenmede etmen olduğu düşünülmektedir (Birsoy 1987; Gürbüz 2007). 

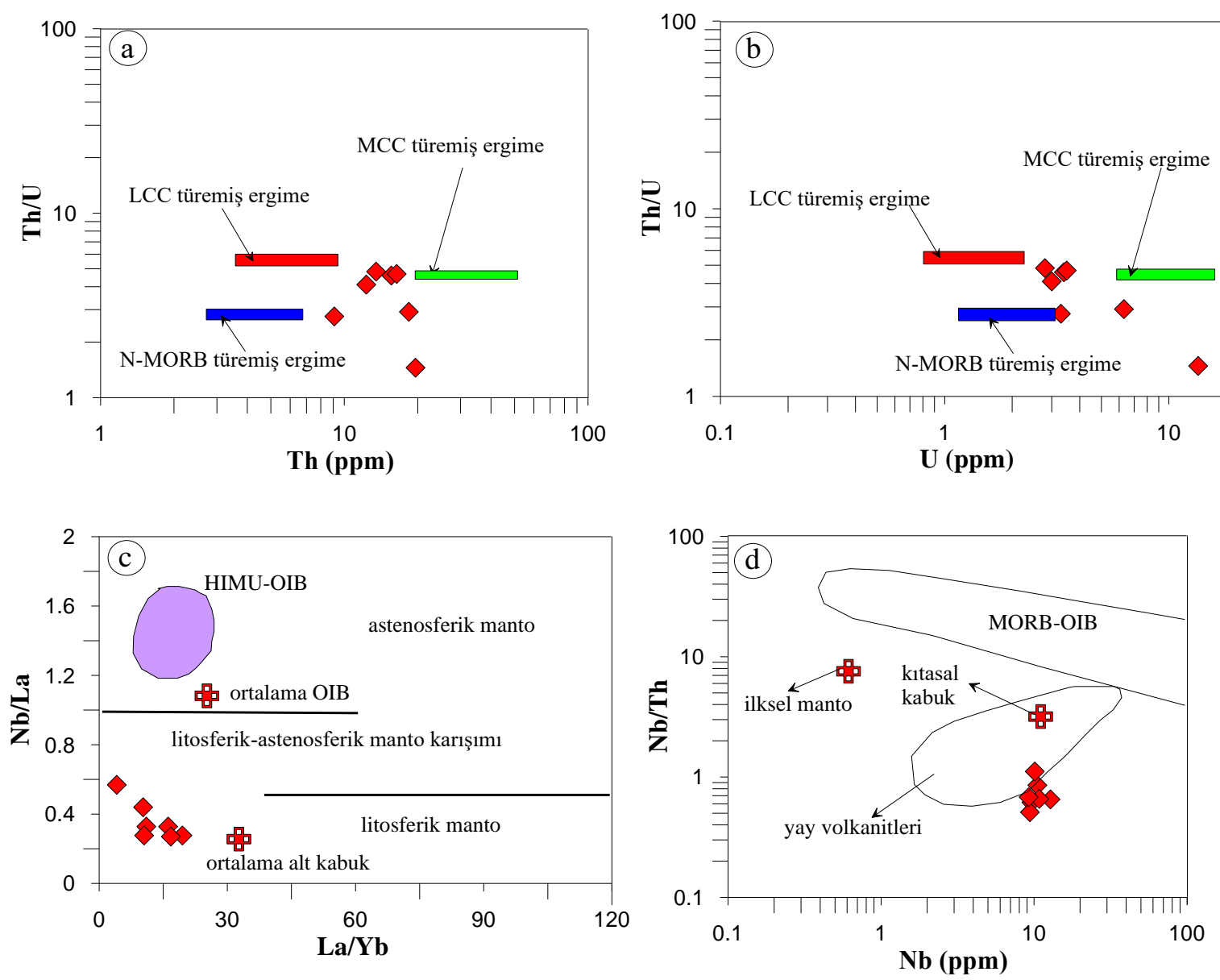

Şekil 8. Musalar Granitin'nin; (a) Th/U'ye karşı Th, (b) Th/U'ye karşı U, (c) Nb/La'ye karşı La/Yb, (d) $\mathrm{Nb} / \mathrm{Th}$ 'ye karşı $\mathrm{Nb}$ diyagramları. LCC, alt kıtasal kabuk; MCC, orta kıtasal kabuk. Alt ve orta kıtasal kabuk değerleri Rudnick ve Gao, 2004, MORB değerleri Sun ve McDought 2008, üst kabuk değerleri Taylor ve McLennan 1985, İlksel manto değerleri Hofmann, 1986, kıtasal kabuk, okyanus ortas1 sırtı bazaltları (MORB), okyanus adası bazaltları (OIB) ve yay volkanitlerine ait değerler Schmidberger ve Hegner (1999), ortalama OIB değerleri Fitton vd., 1991 ve ortalama alt kabuk değerleri Chen ve Arculus, 1995'den alınmıştır. Astenosferik, litosferik ve mixed manto arasındaki sınırlar Smith vd., 1999 ve HIMU-OIB alanı Weaver vd., 1987'den alınmıştır
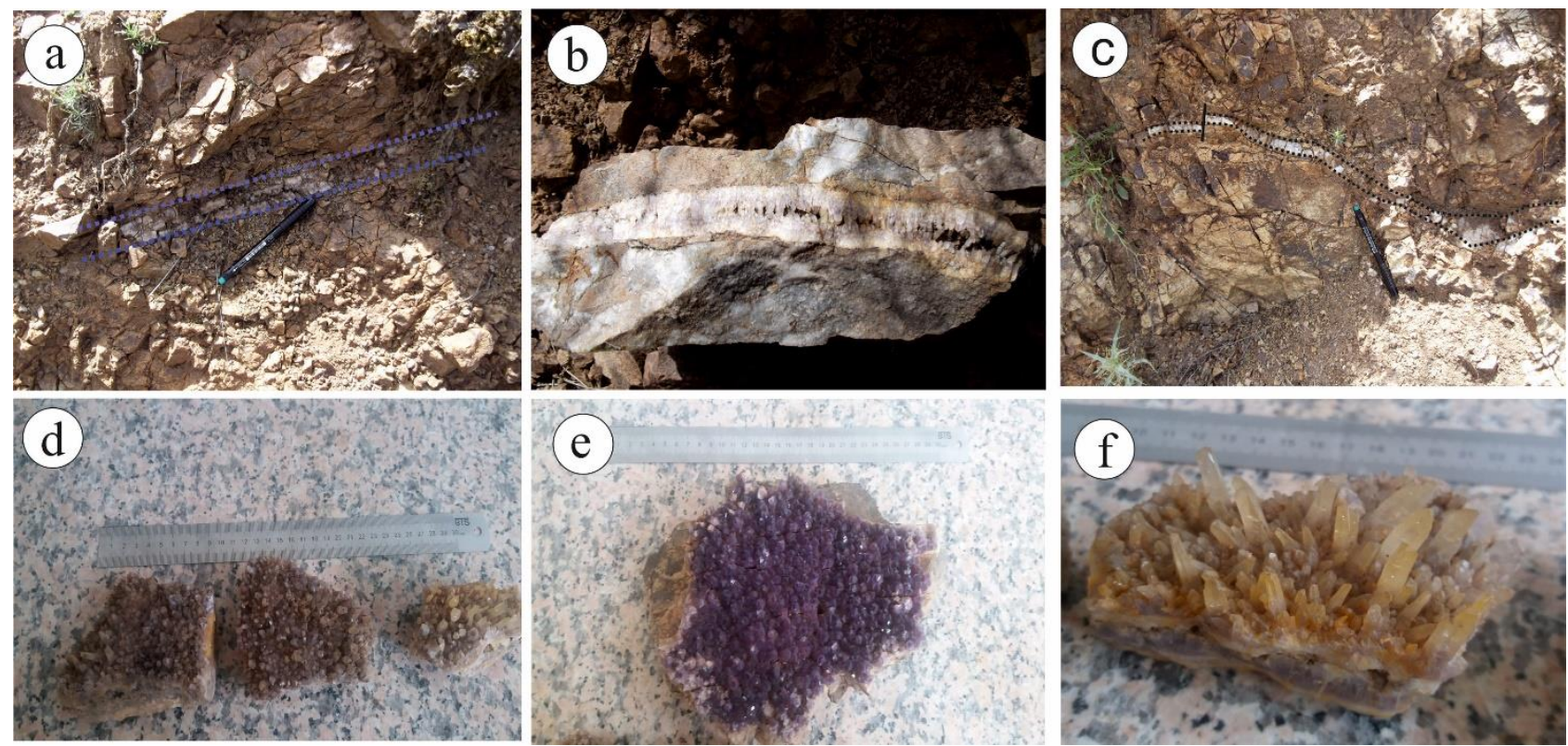

Şekil 9. Yukarıgöçek ametist oluşumları; (a) Çatlak sistemi içerisinde gelişen küçük boyutlu ametist, (b) Çatlak sistemi içerisinde gelişen diş yapılı ametist, (c) Yer yer kırılmış küçük ametist damarları, (d) ve (e) Açık mor-lila renkli ve iri taneli ametist, (f) Sarımsı beyaz renkli ametist kristali 


\subsubsection{Mineral Kimyast}

Yukarıöçek köyündeki HSA-10 nolu çatlakta bulunan ametist kristalinden örnek alınmış ve Minnesota Üniversitesi (ABD) mikroprob laboratuvarında mineral kimyası analizi yaptırılmıştır. HSA-10 nolu çatlakta bulunan iki adet ametisten yapılan analiz sonuçları Tablo 2'de verilmiştir.

$\mathrm{SiO}_{2}$ değerleri HSA-10-66 nolu örnekte merkez noktalarda hafif artışlar olduğu, kenar noktalarda ise düşüş olduğu görülürken HSA-10-67 nolu örnekte $\mathrm{SiO}_{2}$ değerlerinde merkezden kenar noktalarına doğru artış olduğu görülmüştür. Ametis kristaline mor rengi veren $\mathrm{FeO}$ ve $\mathrm{MnO}$ değerleri örneklerde merkez veya kenar kısımlarında $\% \quad 0.0$ ile $\quad 0.02$ arasında değişmektedir. Değerlerin düşük olması çalışılan ametistlerin renginin açık olmasının nedeni olmuş olabilir. $\mathrm{TiO}_{2}$ değerleri HSA-10-66 nolu örnekte merkez noktalarında değer görülmeyip kenar noktalarında çok küçük oranlarda $(\% \quad 0.02-0.01)$ olduğu görülmektedir. HSA-10-66 nolu örnekte $\mathrm{Al}_{2} \mathrm{O}_{3}$ değeri yüksek iken HSA-10-67 nolu örnekte bu değer düşüktür. Tüm bu analiz sonuçları gügü köyündeki (Dursunbey-Balıkesir) ametist değerleri ile benzerdir (Gürbüz, 2007).

Tablo 2. HSA-10 nolu çatlakta bulunan ametist kristalinden mikroprob analiz sonuçları

\begin{tabular}{|c|c|c|c|c|c|c|c|c|c|c|}
\hline $\begin{array}{l}\text { Örnek No } \\
\text { Ölçüm No }\end{array}$ & $\begin{array}{l}\text { HS-10 } \\
66-1 \mathrm{M} .\end{array}$ & $\begin{array}{l}\text { HS-10 } \\
66-2 \mathrm{M} .\end{array}$ & $\begin{array}{l}\text { HS-10 } \\
66-3 \mathrm{M} . \\
\end{array}$ & $\begin{array}{l}\text { HS-10 } \\
66-4 \mathrm{~K} .\end{array}$ & $\begin{array}{l}\text { HS-10 } \\
66-5 \mathrm{~K} .\end{array}$ & $\begin{array}{r}\text { HS-10 } \\
67-1 \mathrm{M} .\end{array}$ & $\begin{array}{l}\text { HS-10 } \\
67-2 \mathrm{M} .\end{array}$ & $\begin{array}{l}\text { HS-10 } \\
67-3 \mathrm{M} .\end{array}$ & $\begin{array}{l}\text { HS- }-10 \\
67-4 \mathrm{~K} .\end{array}$ & $\begin{array}{l}\text { HS-10 } \\
67-5 \mathrm{~K} .\end{array}$ \\
\hline $\mathrm{SiO}_{2}$ & 97.63 & 97.86 & 97.89 & 97.81 & 97.42 & 99.04 & 99.06 & 99.89 & 99.49 & 100.04 \\
\hline $\mathrm{TiO}_{2}$ & 0.00 & 0.00 & 0.00 & 0.02 & 0.01 & 0.00 & 0.00 & 0.02 & 0.00 & 0.00 \\
\hline $\mathrm{Al}_{2} \mathrm{O}_{3}$ & 0.49 & 0.51 & 0.48 & 0.40 & 0.31 & 0.01 & 0.01 & 0.00 & 0.00 & 0.02 \\
\hline $\mathrm{Cr}_{2} \mathrm{O}_{3}$ & 0.01 & 0.00 & 0.00 & 0.01 & 0.00 & 0.00 & 0.00 & 0.00 & 0.00 & 0.00 \\
\hline $\mathrm{FeO}$ & 0.00 & 0.00 & 0.01 & 0.02 & 0.00 & 0.02 & 0.02 & 0.01 & 0.02 & 0.00 \\
\hline $\mathrm{MnO}$ & 0.01 & 0.01 & 0.00 & 0.00 & 0.00 & 0.02 & 0.00 & 0.00 & 0.01 & 0.01 \\
\hline $\mathrm{MgO}$ & 0.00 & 0.00 & 0.00 & 0.00 & 0.00 & 0.00 & 0.00 & 0.00 & 0.00 & 0.02 \\
\hline $\mathrm{CaO}$ & 0.00 & 0.00 & 0.02 & 0.00 & 0.02 & 0.00 & 0.00 & 0.02 & 0.00 & 0.01 \\
\hline $\mathrm{Na}_{2} \mathrm{O}$ & 0.02 & 0.01 & 0.03 & 0.02 & 0.03 & 0.00 & 0.00 & 0.00 & 0.00 & 0.00 \\
\hline $\mathrm{K}_{2} \mathrm{O}$ & 0.00 & 0.00 & 0.00 & 0.04 & 0.03 & 0.00 & 0.00 & 0.02 & 0.00 & 0.00 \\
\hline TOPLAM & 98.16 & 98.39 & 98.43 & 98.32 & 97.82 & 99.09 & 99.09 & 99.96 & 99.52 & 100.10 \\
\hline
\end{tabular}

\subsubsection{Sivı Kapanım}

Yukarıöçek köyü ve civarındaki ametist kristallerinin bulunduğu damarlardan alınan 5 adet ametist kristal örneğinin sıvı kapanım çalıșması İstanbul Teknik Üniversitesi (İTÜ), Sıv1 Kapanım laboratuarında yapılmıştır. İTÜ'de örneklerin ince kesiti yapılarak iki yüzü parlatılmışırı. 5 Adet ametist örneğinden toplam 31 adet sivi kapanım ölçümleri yapilmış ve sonuçlar Tablo 3 'de verilmiştir. Yapılan analizlerde birincil ve ikincil kapanım çeşitleri tespit edilmiştir. En çok gözlenen kapanım çeşidi birincil sıvı bakımından zengin kapanım olmakla beraber ikincil sivı bakımından zengin kapanım ve birincil sıvı buhar kapanım çeşitleri de tespit edilmiştir. (Tablo 3). Sıvı kapanımlardan çekilen mikrofotografların bazılarının görüntüleri Şekil 10'da verilmiştir. Sıv1 kapanımlardan hesaplanan homojenleşme sicaklık değerleri $231{ }^{\circ} \mathrm{C}$ ile $278{ }^{\circ} \mathrm{C}$ arasında olup ortalama $255{ }^{0} \mathrm{C}$ 'dir (Şekil 11, Tablo 3). Son buz kristalindeki ergime sıcaklığından (Tm) yararlanılarak, örneklere ait sıv1 kapanımlarda mevcut tuz miktarı \% olarak hesaplanmıștır (Roedder, 1984; Bodnar, 1993).

Yukarıöçek köyü ve civarındaki ametist kristallerine ait örnekler, Roedder (1984) tarafından hazırlanan tuzluluk-homojenleşme sıcaklığ diyagramında değerlendirilmiştir (Şekil 12a). Buna göre, ametist kristallerinin tuzluluk oranlarının düşük olduğu ve epitermal kökenle ilişkili olduğu görülmektedir. Homojenleşme sıcaklığ sıvı tuzluluk verileriyle birleştirildiğinde, sıvı yakalama koşullarından bağımsız olarak sıvının yoğunluğunu tanımlar. Siv1 yoğunluğundaki değişiklikler, sıvı akış mekanizmaları ve değerlendirme açısından özellikle önemlidir (Wilkinson, 2001). Çalışılan ametistlerin verileri sıvı yoğunluk diyagramına aktarıldığında (Şekil 12b), düşük sıvı yoğunluklu hidrotermal kökene işaret etmektedir. $\mathrm{Bu}$ sonuçlara göre Yukarıgöçek köyü ametistlerin ortalama oluşum sıcaklığı $255{ }^{\circ} \mathrm{C}$ civarında olup hidrotermal yolla oluşmuş olabilir. 
Tablo 3. Yukarıgöçek köyü ve civarındaki ametist kristallerinin sıvı kapanım analiz sonuçları

\begin{tabular}{|c|c|c|c|c|c|c|c|}
\hline $\begin{array}{l}\text { Örnek } \\
\text { No }\end{array}$ & $\begin{array}{c}\text { Homojen } \\
\text { Sicaklık } \\
\text { Th }\left({ }^{\circ} \mathrm{C}\right)\end{array}$ & $\begin{array}{c}\text { Ötektik } \\
\text { Sicaklık } \\
(\mathrm{Te})\left({ }^{\circ} \mathrm{C}\right)\end{array}$ & $\begin{array}{c}\text { Son } \\
\text { Erime } \\
\text { Sicaklık } \\
(\mathrm{Tm})\left({ }^{\circ} \mathrm{C}\right)\end{array}$ & $\begin{array}{c}\text { Sivı } \\
\text { Faz } \\
(\mu \mathrm{m} 2)\end{array}$ & $\begin{array}{c}\text { Buhar } \\
\text { Faz } \\
(\mu \mathrm{m} 2)\end{array}$ & $\begin{array}{c}\text { Tuzluluk } \\
\text { (NaCl) } \\
(\%)\end{array}$ & Kapanım Türü \\
\hline HSA1_1 & 257.8 & -52.5 & -1.0 & 546.7 & 99.4 & 1,74 & Birincil, Sıv1-Buhar Kap, Sıvıca Zengin Kap. \\
\hline HSA1_2 & 251.5 & -51.5 & -0.1 & 91.5 & 17 & 0.18 & Birincil, Sivı-Buhar Kap, Sivıca Zengin Kap. \\
\hline HSA1_3 & 238.5 & -55.2 & -0.8 & 22.4 & 6.2 & 1.40 & Birincil, Sıvı-Buhar Kap, Sıvıca Zengin Kap. \\
\hline HSA1_4 & 238.1 & -54 & -0.8 & 17.7 & 6.6 & 1.40 & Birincil, Sıvı-Buhar Kap, Sıvıca Zengin Kap. \\
\hline HSA1_5 & 243.3 & -51 & -0.8 & 34.6 & 8.2 & 1.40 & Birincil, Sıv1 Buhar-Kap, Sıvıca Zengin Kap. \\
\hline HSA1_6 & 255.6 & -20 & -0.8 & 63.8 & 12.5 & 1.40 & Birincil, Sıvı-Buhar Kap, Sıvıca Zengin Kap. \\
\hline HSA1_7 & 238.1 & -58.8 & -0.8 & 73.7 & 13.5 & 1.40 & Birincil, Sıvı-Buhar Kap., Sıvıca Zengin Kap. \\
\hline HSA1_8 & 235 & -23.3 & -6.3 & 112.9 & 21.2 & 9.60 & Birincil, Siv1-Buhar Kap, Sıvıca Zengin Kap. \\
\hline HSA2_1 & 244 & -18.8 & -2.6 & 17.6 & 4.4 & 4.34 & İkincil, Sıvı Bakımından Zengin Kap. \\
\hline HSA2_2 & 261 & -20.1 & -0.4 & 96.4 & 16.9 & 0.70 & İkincil, Sıvı Bakımından Zengin Kap. \\
\hline HSA2_3 & 275 & 0.8 & -0.8 & 56.6 & 23.5 & 1.40 & Birincil, Sıv1 Bakımından Zengin Kap. \\
\hline HSA2_4 & 278 & -0.4 & -0.4 & 148.2 & 51.5 & 0.70 & Birincil, Sıv1 Bakımından Zengin Kap. \\
\hline HSA2_5 & 260 & -20.8 & -2.9 & 80.9 & 20 & 4.80 & İkincil, Sıv1 Bakımından Zengin Kap. \\
\hline HSA3_1 & 252.1 & -3.1 & -1.4 & 38.4 & 7.7 & 2.41 & İkincil, Sıvı Bakımından Zengin Kap. \\
\hline HSA3_2 & 264.3 & -1.9 & -1.3 & 45.8 & 5.7 & 2.24 & İkincil, Sıvı Bakımından Zengin Kap. \\
\hline HSA3_3 & 232 & -21.7 & -1.3 & 32.2 & 6.2 & 2.24 & Birincil, Sıv1 Bakımından Zengin Kap. \\
\hline HSA3_4 & 231 & -20.3 & -1.9 & 32.5 & 7.7 & 3.23 & Birincil, Sıv1 Bakımından Zengin Kap. \\
\hline HSA3_5 & 260.1 & -22.9 & -1.1 & 115.3 & 25.8 & 1.91 & İkincil, Sıv1 Bakımından Zengin Kap. \\
\hline HSA4_1 & 268.6 & -57.1 & -0.9 & 63.6 & 16.8 & 1.57 & İkincil, Sıvı Bakımından Zengin Kap. \\
\hline HSA4_2 & 265.1 & -28.7 & -0.8 & 42.8 & 9.4 & 1.40 & Birincil, Sıv1 Bakımından Zengin Kap. \\
\hline HSA4_3 & 252.2 & -1.7 & -1.1 & 73.9 & 12.5 & 1.91 & Birincil, Sıv1 Bakımından Zengin Kap. \\
\hline HSA4_4 & 244.1 & -21.1 & -1.1 & 53.2 & 8.8 & 1.91 & Birincil, Sıv1 Bakımından Zengin Kap. \\
\hline HSA4_5 & 248.4 & -44.9 & -1.5 & 140.7 & 24.5 & 2.57 & Birincil, Sıvı Bakımından Zengin Kap. \\
\hline HSA10_1 & 264.5 & -56.4 & -2.8 & 92.2 & 17.2 & 4.65 & Birincil, Sıv1 Bakımından Zengin Kap. \\
\hline HSA10_2 & 268.2 & -43.7 & -1.4 & 61.5 & 16.1 & 2.41 & Birincil, Sıv1 Bakımından Zengin Kap. \\
\hline HSA10_3 & 258.5 & -1.9 & -1.2 & 269.1 & 47.7 & 2.07 & Birincil, Sıv1 Bakımından Zengin Kap. \\
\hline HSA10_4 & 257 & -2.1 & -1.2 & 210 & 21.9 & 2.07 & Birincil, Sıv1 Bakımından Zengin Kap. \\
\hline HSA10_5 & 263.2 & -2.2 & -1.0 & 153.4 & 23.5 & 1.74 & Birincil, Sıv1 Bakımından Zengin Kap. \\
\hline HSA10_6 & 260.9 & -23.2 & -2.3 & 157.9 & 36.3 & 3.87 & Birincil, Sıvı Bakımından Zengin Kap. \\
\hline HSA10_7 & 257.7 & -22.8 & -2.5 & 47.9 & 12.6 & 4.18 & Birincil, Sıv1 Bakımından Zengin Kap. \\
\hline HSA10_8 & 256 & -20.1 & -2.3 & 106.4 & 23.9 & 3.87 & Birincil, Sıv1 Bakımından Zengin Kap. \\
\hline
\end{tabular}

Kap.: Kapanım

\subsubsection{Ametist Kristalinin Oluşum Mekanizması}

Hidrotermal çözeltiler genellikle magma kökenli sıvı ve gazlardan oluşmuşlardır. Bu çözeltiler bünyelerine magmadan aldıkları iz elementlerle çevresinde bulunan kayaçların çatlaklarına taşınırlar. Böylece çeşitli elementlerce zenginleşen bu sıvılar yeterli doygunluğa ulaştığında kristallenmeye başlar. Sonuçta kayaçların çatlak ve boşluklarında çeşitli mineral damarlarını oluştururlar. Bu mineral damarlarında ametist, topaz ve zümrüt gibi değerli mücevher taşları da oluşabilir. Ametist hidrotermal kökenli metalik cevher yataklarında görünen mücevher taşıdır.

Yukarı̈öçek köyü ve çevresinde Fe, Mg ve Mn'ca zengin üst Kretase yaşlı ofiyolitik kayaçlar bulunmaktadır. Batı Anadolu bölgesi tektonik açıdan hareketli olup mevcut kayaçlar bunun etkisi ile oldukça kırıklı bir yapı sunmaktadır. Tersiyer döneminde ise bölgede yoğun magmatizma görülmektedir (Y1lmaz, 1990; Okay ve Tüysüz, 1999; Aldanmaz vd., 2000; Altunkaynak ve Genç, 2008; Karacık vd., 2008; Prelevic' vd., 2012; Aslan vd. 2017). Bunun örneklerinden biri de çalışma alanındaki Musalar granitidir. Asidik karakterli Musalar granitinin 
ofiyolitik melanjı kesmiş ve beraberinde getirmiş olduğu silisçe zengin sıvıları ofiyolitik melanj içindeki çatlarara bırakmıştır. Ortalama 255 ${ }^{\circ}$ C'deki sıvı faz ofiyolitik melanj içindeki çatlaklarda hidrotermal evrede, yan kayaçtan Fe, Mn gibi elemetleride alarak mor-lila rengi kuvars kristalleri (ametist) halinde oluşumunu tamamlamıştır.
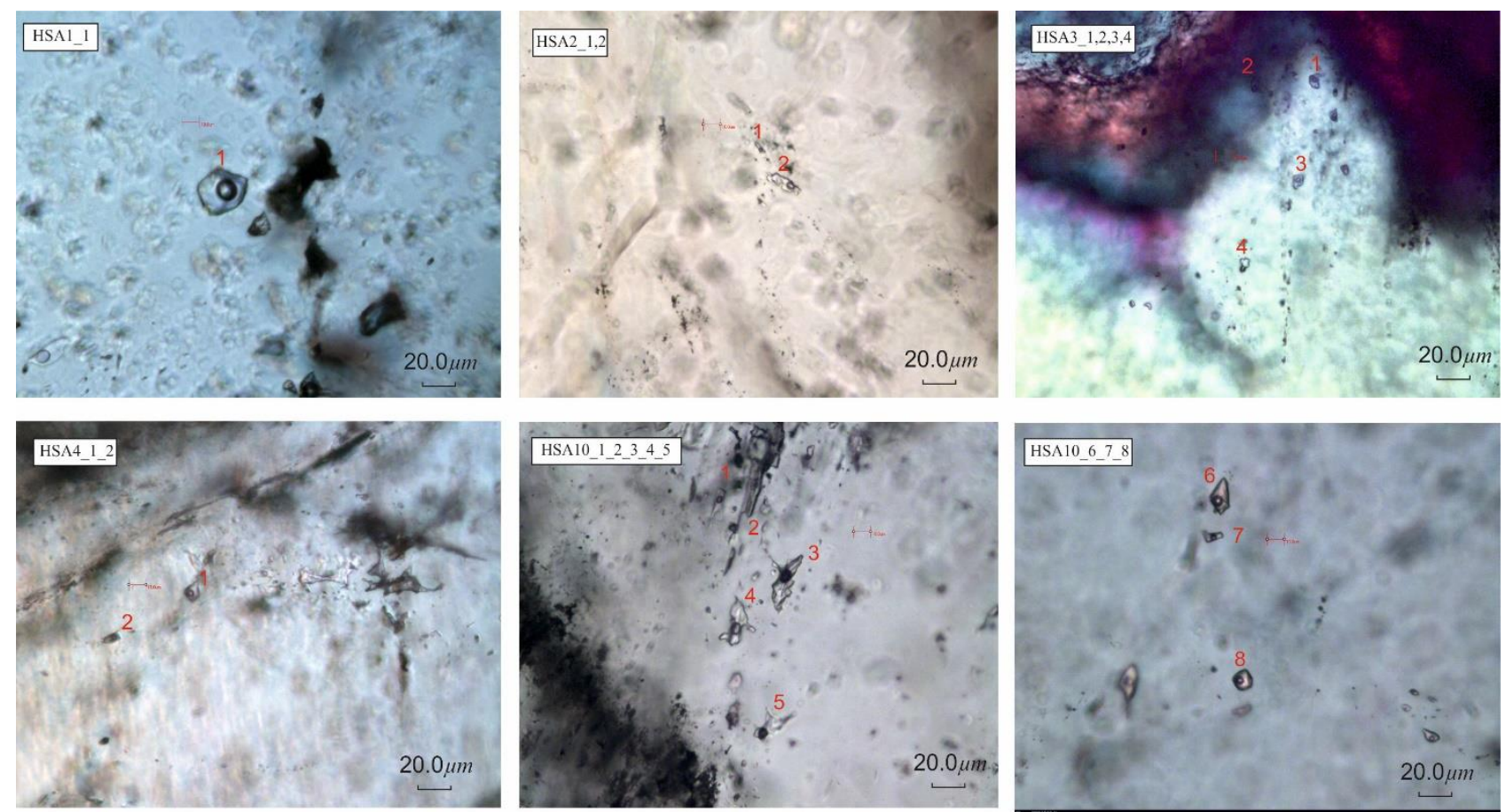

Şekil 10. Yukarıgöçek köyü ametistlerine ait birincil ve ikincil sıvı kapanım çeşitleri

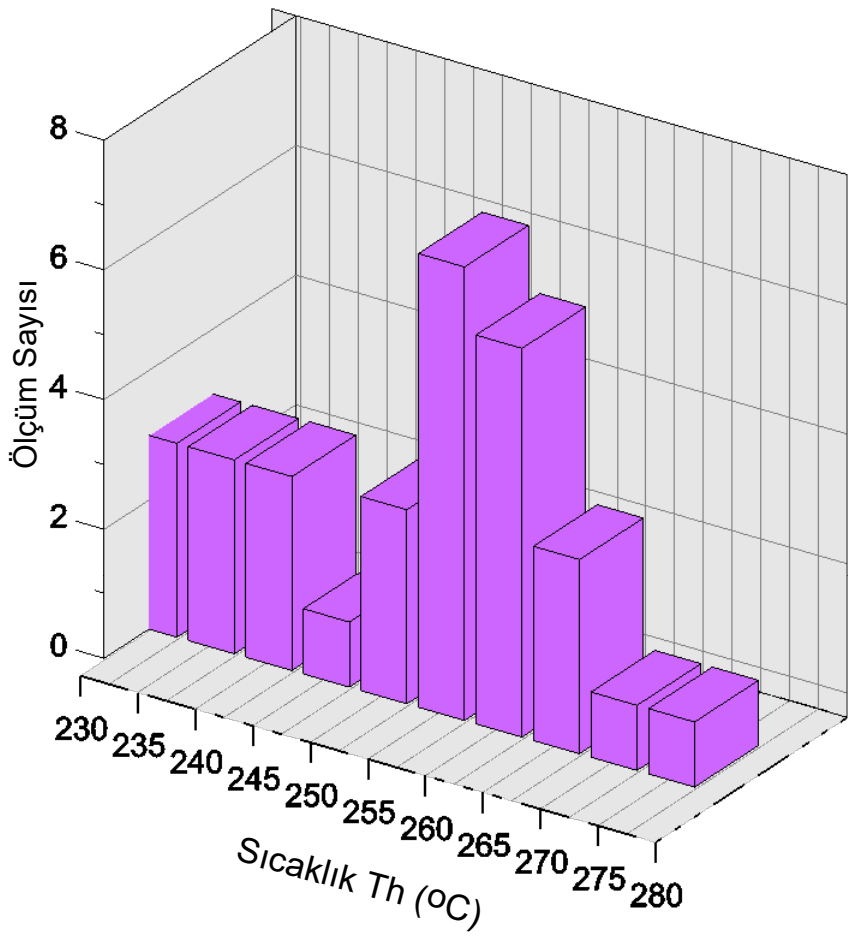

Şekil 11. Yukarıgöçek köyü ametistlerinin homojenleşme diyagramı 

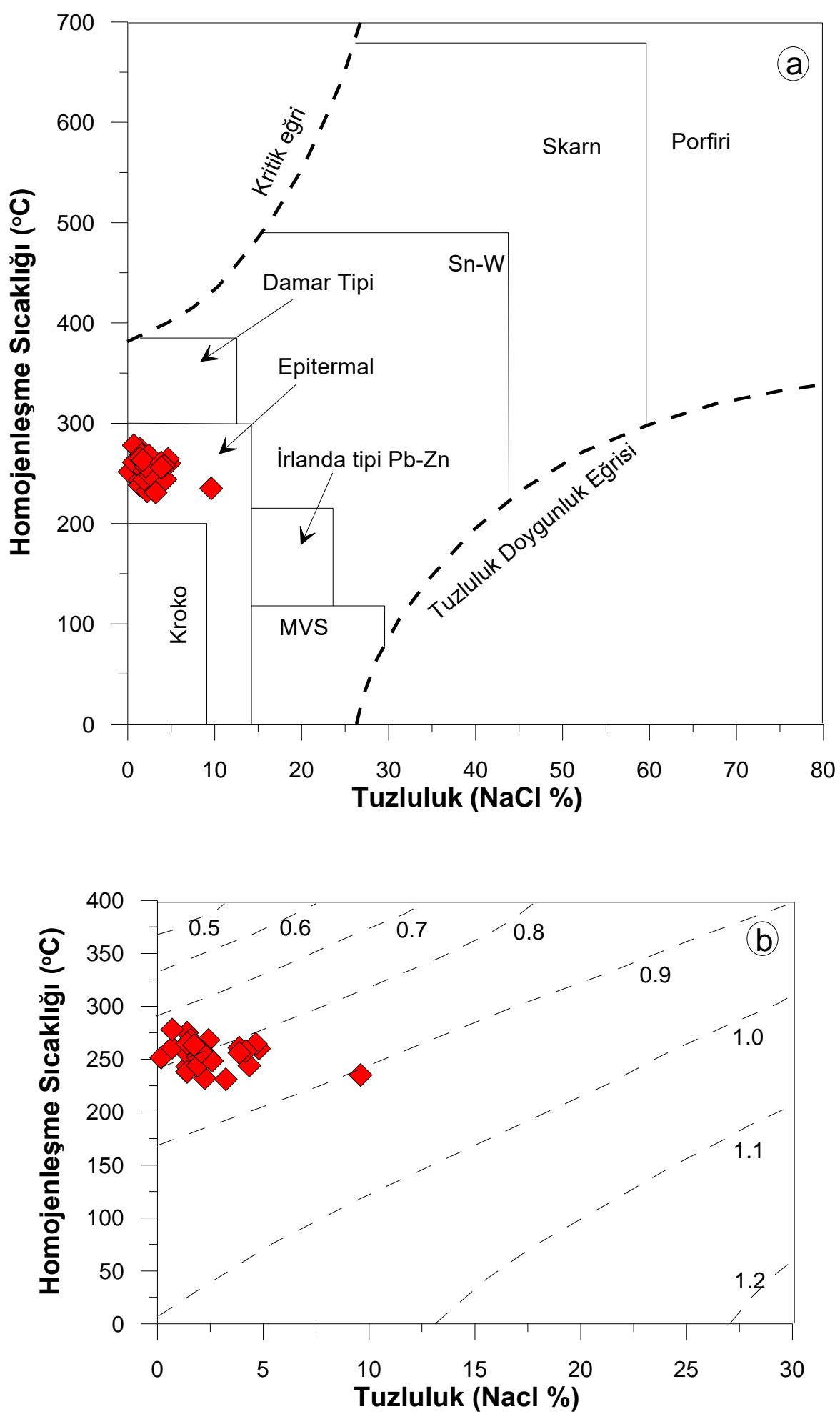

Şekil 12. Ametist örneklerine ait; (a) Yatak tiplerine ait tuzluluk-homojenleşme sıcaklığı değişim diyagramı (MVS: Misisipi Vadisi masif sülfit yatakları) (Roedder, 1984), (b) Buhara doymuş $\mathrm{NaCl}-\mathrm{H}_{2} \mathrm{O}$ çözeltilerinin yoğunluklarını $\left(\mathrm{g} / \mathrm{cm}^{-3}\right)$ gösteren sıcaklık-tuzluluk grafiği. Konturlar, FLINCOR bilgisayar programı (Brown, 1989) kullanılarak Zhang ve Frantz (1987) tarafından üretilen denklem verilerinden alınmıştır. 


\section{Sonuçlar}

Granit ve granodiyorit bileşimli kayaçlardan oluşan Musalar graniti orta ve iri taneli yer yer de poikilitik dokuda olup ana mineral olarak plajiyoklaz, ortoklaz, kuvars, biyotit, amfibol ve opak mineral içermektedir.

Jeokimyasal olarak Musalar sokulumu ortayüksek potasyumlu kalkalkalen karakterinde olup I-tipi ve peralümin özelliği göstermektedir. Hafif nadir toprak elementler kondrit değerine göre daha zenginleşmiştir. Tektonik olarak Musalar graniti çarpışma sonrası volkanik yay granitlerinin özelliklerini göstermektedir. Oluşumunda, litosferik manto ile kabuktan türemiş magmanın birlikte rol oynadığ 1 görülmektedir. LILE elementlerince zenginleşme ve $\mathrm{Nb}$, Ta gibi elemenlerdeki negatif anomaliler metazomatik mantoyu işaret etmektedir.

Yukarıgöçek köyü ve civarında bulunan ametistler özellikle ofiyolitik kayaçların kırık ve çatlak sistemlerinde 4-5 $\mathrm{cm}$ arasındaki kalınlıklarda olup damarlar şeklinde görülmektedir. Ametistlerin kök ve diş kısımları net olarak gözlemlenmektedir. Kristal rengi genellikle açık mor veya liladir. Ametist kristaline mor rengi veren $\mathrm{FeO}$ ve $\mathrm{MnO}$ değerleri örneklerde merkez veya kenar kısımlarında \%0.0 ile 0.02 arasinda değişmektedir. Değerlerin düşük olması ametistlerin renginin açı olmasının nedeni olabilir. Ametistlerin Homojenleşme sicaklık değerleri $231{ }^{\circ} \mathrm{C}$ ile $278{ }^{\circ} \mathrm{C}$ arasında olup ortalama $255{ }^{\circ} \mathrm{C}$ 'dir. Çalışılan ametist kristallerinin tuzluluk oranlarının düşük olduğu ve epitermal kökenle ilişkili olduğu görülmektedir. Benzer şekilde, ametist örnekleri düşük sıvı yoğunluklu olup hidrotermal kökene işaret etmektedir. Yukarıgöçek köyü ametistleri Musalar granitinin ofiyolitik melanj1 kesmesi ve beraberinde getirmiş olduğu silisçe zengin sıv1 fazı $255{ }^{\circ} \mathrm{C}^{\prime} \mathrm{de}$ hidrotermal evrede melanj içindeki mevcut çatlaklara bırakması ile oluşmuştur. Yukarıgöçek köyü civarında yüzeye yakın damarlarda bulunan ametist kristallerinin çabucak dağılması, kopması sonucunda takı yapımında kullanılmaya elverişli değildir. Fakat mevcut damarların bulunduğu yerlerden daha derinlere doğru yapılacak olan detaylı arama teknikleriyle daha iyi kristal örneklerine ulaşılabilir.

\section{Katkı Belirtme}

$\mathrm{Bu}$ çalışma Balıkesir Üniversitesi Proje Araştırmaları Birimi tarafından 2014/141 nolu proje ile desteklenmiştir ve birinci yazarın Yüksek
Lisans Tez çalışmasını oluşturmaktadır. Arazi çalışmalarındaki yardımlarından dolayı Jeoloji Yüksek Mühendisi İsmail ALTIN'a çok teşekkür ederiz. Yazarlar, makaleye yapıcı eleştiri ve görüşleriyle katkı sağlayan dergi editörleri ve hakemlere teşekkür eder.

\section{Kaynaklar}

Akay, E., 2009. Geology and Petrology of The Simav Magmatic Complex (NW Anatolia) and Its Comparison With The Oligo-Miocene Granitoids In NW Anatolia: Implications on Tertiary Tectonic Evolution of The Region. International Journal of Earth Sciences, 98, 1655-1675.

Aldanmaz, E., Pearce, J., Thirlwall, M.F. ve Mitchell, J., 2000. Petrogenetic Evolution of Late Cenozoic, Postcollision Volcanism in Western Anatolia, Turkey. Journal of Volcanology and Geothermal Research, 102, 67-95.

Altunkaynak, Ş., 2007. Collision-Driven Slab Breakoff Magmatism in Northwestern Anatolia, Turkey. The Journal of Geology, 115(1), 63-82.

Altunkaynak, Ş., ve Yılmaz, Y., 1998. The Mount Kozak Magmatic Complex, Western Anatolia. Journal of Volcanology and Geothermal Research, 85, 211-231.

Altunkaynak, S. ve Genç, Ş.C., 2008. Petrogenesis and Time-Progressive Evolution of The Cenozoic Continental Volcanism in The Biga Peninsula, NW Anatolia (Turkey). Lithos, 102, 316-340.

Altunkaynak, S.., Sunal, G., Aldanmaz, E., Genç, C.Ş., Dilek, Y. ve Furnes, H., 2012. Eocene Granitic Magmatism in NW Anatolia (Turkey) Revisited: New Implications From Comparative Zircon SHRIMP U-Pb and 40Ar-39Ar Geochronology and Isotope Geochemistry on Magma Genesis and Emplacement. Lithos, 55, 289-309.

Aslan, Z., Erdem, D., Temizel, İ. ve Aslan, M., 2017. SHRIMP U-Pb Zircon Ages and Whole-Rock Geochemistry For The Şapçı Volcanic Rocks, Biga Peninsula, Northwest Turkey: Implications for Preeruption Crystallization Conditions and Source Characteristics. International Geology review, 59(14), 1764-1785.

Bachelor, R.A. ve Bowden, P., 1985. Petrogenetic Interpretation of Granitoid Rock Series Using Multicationic Parameters. Chemical Geology, 48, 43-55.

Balitsky, V.S., Machina, I.B., Mar, A.A., Shigley, J.E., Rossman, G.R. ve Lu, T., 2000. Industrial Growth, Morphology and Some Properties of Bi-Colored Amethyst-Citrine Quartz 
(Ametrine). Journal of Crystal Growth, 212(12), 255-260.

Birsoy, R., 1983. Kuvarsın Renklenmesi ve Yapısal Hataları, TÜBİTAK Temel Bilimler Araştırma Grubu, Proje No: TBAG-468, 101 s.

Birsoy, R., 1987. Doğal Ametistin Kirlilik İçeriği ve Renklenmesi. Türkiye Jeoloji Bülteni, 30(2), 63-66.

Brown, P.E., 1989. FLINCOR: A Microcomputer Program For The Reduction and Investigation of Fluid Inclusion Data. American Mineralogist, 74, 1390-1393.

Bodnar, R.J., 1993. Revised Equation and Table for Determining the Freezing Point Depression of $\mathrm{H} 2 \mathrm{O}-\mathrm{NaCl}$ Solutions. Geochmical Cosmochimca Acta, 57, 683-684.

Chen, W. ve Arculus, R. J., 1995. Geochemical and Isotopic Characteristics of Lower Crustal Xenoliths, San Francisco Volcanic Field, Arizona, U.S.A. Lithos, 110, 99-119.

Cohen, A.J. ve Hassan, F., 1974. Ferrous and Ferric Ions in Synthetic A-Quartz and Natural Amethyst. American Mineralogist Journal of Earth and Planetary Materials, 59(7-8), 719728.

Delaloye, M. ve Bingöl, E., 2000. Granitoids From Western and Northwestern Anatolia: Geochemistry and Modeling of Geodynamic Evolution. International Geology Review, 42, 241-268.

Dönmez, M., Akçay, A. E., Genç, Ş.C. ve Acar, Ş., 2005. Biga Yarımadasında Orta-Üst Eosen Volkanizması ve Denizel İgnimbiritler. Maden Tetkik ve Arama Dergisi, 131, 49-61.

Duru, M., Pehlivan, Ş., Şentürk, Y., Yavaş F. ve Kar, H., 2004. New Results on The Lithostratigraphy of The Kazdağ Massif in Northwest Turkey. Turkish Journal of Earth Sciences, 13, 177-186.

Ercan, T., Satır, M., Steinitz, G., Dora, A., Sarıfakıŏlu, E. ve Adis, C., 1995. Biga Yarımadası ile Gökçeada, Bozcaada ve Tavşan Adalarındaki (KB Anadolu) Tersiyer Volkanizmasının Özellikleri. Maden Tetkik Arama Enstitüsü Dergisi, 117, 55-86.

Fitton, J.G., 1989. Petrology and Geochemistry of Late Cenozoic Basalt Flows, Western Grand Canyon, Arizona, in Geology of Grand Canyon, In: Elston, D.P., Billingstey, G.G., Young, R.A., (Eds.), Northern Arizona, Field Trip. AGU, Guideb, 186-189.

Genç, Ş.C., 1998. Evolution of The Bayramiç Magmatic Complex, Nortwestern Anatolia.
Journal of Volcanology and Geothermal Research, 85, 233-249.

Gürbüz. M., 2007. Güğü (Dursunbey-Balıkesir) Civarındaki Ametistlerin Oluşumunun İncelenmesi. Doktora Tezi, Çukurova Üniversitesi Fen Bilimleri Enstitüsü. Adana, 152 s.

Hatipoğlu, M., 2003. Güğü Köyü Ametist Kristallerinin Değerlendirilmesi (Dursunbey, Balıkesir, KB Türkiye) ve Yöresel Ekonomiye Katkıs1. Türkiye IV. Mermer Sempozyumu Bildiriler Kitab1, 243-256.

Hofmann, A.W., 1988. Chemical Differentiation of The Earth: The Relationship Between Mantle, Continental Crust, and Oceanic Crust. Earth and Planetary Science Letters, 90, 297-314.

Irvine, T.N. ve Baragar, W.R.A., 1971. A Guide to The Chemical Classification of Common Volcanic Rocks. Canadian Journal of Earth Science, 8, 523-548.

İçözü, T., 2001. Some Example Displaying in The Productivity of The Anatolian Gemological Potential. Doktora Tezi. İzmir Dokuz Eylül Üniversitesi Fen Bilimleri Enstitüsü. İzmir 139s.

Karacık, Z., Yılmaz, Y., Pearce, J.A. ve Ece, Ö.I., 2008. Petrochemistry of The South Marmara Granitoids, Northwest Anatolia, Turkey. International Journal of Earth Sciences, 97, 1181-1200.

Le Maitre, R.W., Streckeisen, A., Zanettin, B., Le Bas, M.J., Bonin, B., Bateman, P., Bellieni, G., Dudek, A., Efremova, S., Keller, J., Lamere, J., Sabine, P.A., Schmid, R., Sorensen, H. ve Woolley, A.R., 2002. Igneous Rocks: A Classification and Glossary of Terms, Recommendations of The International Union of Geological Sciences, Subcommission of The Systematics of Igneous Rocks. Cambridge University Press, 336 s.

Maniar, P.D. ve Piccoli, P.M., 1989. Tectonic Discrimination of Granitoids. Geological Society of America Bulletin, 101(5), 635-643.

Middlemost, E.A.K., 1994. Naming Material in The Magma/Igneous Rock System. Earth-Science Reviews, 37, 215-224.

Miyashiro, A., 1978. Nature of Alkalic Volcanic Rock Series. Contributions to Mineralogy and Petrology, 66, 91-104.

Okay, A.İ., 2008. Geology of Turkey: A Synopsis. Anschnitt, 21, 19-42.

Okay, A.İ. ve Tüysüz, O., 1999. Tethyan Suture of Northern Turkey, In: Durand, B., Jivet, L., 
Horvath, F. ve Seranne, M., (Eds.), The Mediterranean Basins; Tertiary Extension Within The Alpine Orogen. Geological Society of Londan, Special Pubication, 156, 475-515.

Okay, A.İ. ve Satır, M., 2006. Geochronology of Eocene Plutonism and Metamorphism in Northwest Turkey: Evidence For A Possible Magmatic Arc. Geodinamica Acta, 19(5), 251266.

Okay A.İ., Tüysüz, O., Satır, M., Özkan-Altıner, S., Altıner, D., Sherlock, S. ve Eren, R.H., 2006. Cretaceous and Triassic Subduction-Accretion, HP/LT Metamorphism and Continental Growth in The Central Pontides, Turkey. Geological Society of America Bulletin, 118, 1247-1269.

Özgenç, İ. ve İlbeyli, N., 2008. Petrogenesis of The Late Cenozoic Eğrigöz Pluton in Western Anatolia, Turkey: Implications for Magma Genesis and Crustal Processes. International Geology Review, 50, 375-391.

Pearce, J.A, Haris, N.B. W. ve Tindle, A.G., 1984. Trace Element Discrimination Diagrams for The Tectonic Interpretation of Granitic Rocks. Journal of Petrology, 25, 956-983.

Pehlivan, Ş., Duru. M., Dönmez, M., Ilgar, A., Akçay, A.E., Erdoğan, K. ve Özer, D., 2007. Türkiye Jeolojisi Haritaları No:96, Balıkesir-İ 19 Paftası. Maden Tetkik Arama Genel Müdürlüğü, Ankara $40 \mathrm{~s}$.

Prelevic', D., Akal, C., Foley, S.F., Romer, R.L., Stracke, A. ve Van Den Bogaard, P., 2012. Ultrapotassic Mafic Rocks As Geochemical Proxies for Post-Collisional Dynamics of Orogenic Lithospheric Mantle: The Case of Southwestern Anatolia, Turkey. Journal of Petrology, 53, 1019-1055.

Roedder, E., 1984. Fluid Inclusions. Reviews in Mineralogy, v. 12, Mineralogical Society of America, Washington, $644 \mathrm{~s}$.

Rudnick, R.L. ve Gao, S., 2004. Composition of The Continental Crust. Treatise on Geochemistry, 3, $1-65$.

Schmidberger, S.S. ve Hegner, E., 1999. Geochemistry and Isotope Ststematics of Calc-Alkaline Volcanic Rocks From The Saar-Nahe Basin (SW Germany)-Implications for Late Variscan Orogenic Development. Contributions to Mineralogy and Petrology, 135, 373-385.

Smith, E.I., Sanchez, A., Walker, J.D. ve Wang, K.F., 1999. Geochemistry of Mafic Magmas in The Hurricane Volcanic Field, Utah: Implications for Small- and Large-Scale Chemical Variability of The Lithospheric Mantle. Journal of Geology, 107, 433-448.
Sun, S. ve McDonough, W.F., 1989. Chemical and Isotopic Systematics of Oceanic Basalt: Implications for Mantle Composition and Processes, In: Saunders, A.D. ve Norry, M.J., (Eds.), Magmatism in The Ocean Basins. Geological Society of London Special Publication, 42, 313-345.

Şengör, A.M.C. ve Y1lmaz, Y., 1981. Tethyan Evolution of Turkey: A Plate Tectonic Approach. Tectonophysics, 75, 181-241.

Taylor, S.R. ve McLennan, S.M., 1985. The Continental Crust, Its Composition and Evolution. Blackwell, Oxford, 312p.

Thirlwall, M.F., Smith, T.E., Graham, A.M., Theodorou, N., Hollings, P. ve Davidson, J.P., 1994. High Field Strength Element Anomalies in Arc Lavas: Source or Processes. Journal of Petrology, 35, 819-838.

Thiéblemont D. ve Tégyey M., 1994. Une Discrimination Géochimique Des Roches Différenciées Témoin de la Diversité d'origine et de Situation Tectonique Des Magmas CalcioAlcalins. Comptes Rendus de l'Académie des Sciences, 319, 87-94.

Thompson, R.N., Morrison, M.A., Hendry, G.L. ve Parry, S.J., 1984. An Assessment of The Relative Roles of Crust and Mantle in Magma Genesis: An Elemental Approach. Philos Translate Society London, A310, 549-590.

Weaver, B.L., Wood, D.A., Tarney, J. ve Joron, J., 1987. Geochemistry of Ocean Island Basalt From The South Atlantic. Ascension, Bouvet, St. Helena, Gough and Tristan da Cunda. In: Fitton, J.G., Upton, B.G.J., (eds.), Alkaline Igneous Rocks. Journal of Geology Society London Special Publication, 30, 253-267.

Wilkinson, J.J., 2001. Fluid Inclusions in Hydrothermal Ore Deposits. Lithos, 55, 229-272.

Wilson, F.H., 1989. Geologic Setting, Petrology and Age of Plicene to Holocene Volcanoes of The Stepovak Bay Area, Western Alaska Peninsula, In: Dover, J.H., Galloway, J.P., (Eds.), Geological Studies in Alaska by The U.S. Geological Survey, United State Geological Survey Bulletin, 1903, 84-95.

Wood, D.A. ve Joron, J.L., (1979). Elemental and Sr İzotopic Variations in Basic Lava From Iceland and Surrounding Ocean Floor: The Nature of The Mantle Sources Inhomogenities. Contribition and Mineralogy Petrology, 70, 319339.

Yiğit, Ö., 2009. Mineral Deposits of Turkey in Relation to Tethyan Metallogeny. Implications 
for Future Mineral Exploration. Economic Geology, 104, 19-51.

Y1lmaz, Y., 1990. Comparision of Young Volcanic Associations of Western and Eastern Anatolia Under Conpressional Regime; A Review. Journal of Volcanology and Geothermal Research, 44, 69-87.

Yılmaz, Y., Genç, Ş.C., Gürer, O.F., Bozcu, M., Y1lmaz, K., Karacik, Z., Altunkaynak, Ş. ve Elmas, A., 2000. When Did The Western Anatolian Grabens Begin to Develop? In: Bozkurt, E., Winchester, J.A., Piper, J.A.D., (eds.), Tectonics and Magmatism in Turkey and The Surrounding Area. Journal of Geology Society London Special Publication,173, 353384.
Yılmaz, Y., Genç, S.C., Karacik, Z. ve Altunkaynak, Ş., 2001. Two Contrasting Magmatic Associations of NW Anatolia and Their Tectonic Significance. Journal of Geodynamics, 31, 243-271.

Yüzer, E.ve Tunay, G., 2012. Biga Yarımadası'nın Genel ve Ekonomik Jeolojisi. Maden Tetkik ve Arama Genel Müdürlüğü, Ankara, 326s.

Zhang, Y.G. ve Frantz, J.D., 1987. Determination of the Homogenization Temperatures and Densities of Supercritical Fluids in the System $\mathrm{NaCl}-\mathrm{KCl}-\mathrm{CaCl} 2-\mathrm{H} 2 \mathrm{O}$ Using Synthetic Fluid Inclusions. Chemical Geology, 64, 335-350. 